\title{
SERCA activity is reduced in $D J-1$ mutant flies and human cells due to oxidative modification
}

\author{
Cristina Solana-Manrique ${ }^{1,2}$, Verónica Muñoz-Soriano ${ }^{1,2}$, \\ Francisco José Sanz ${ }^{1,2}$ and Nuria Paricio ${ }^{1,2, *}$
}

${ }^{1}$ Departamento de Genética, Facultad CC Biológicas, Universidad de Valencia, 46100 Burjassot, Spain

${ }^{2}$ Instituto Universitario de Biotecnologia y Biomedicina (BIOTECMED), Universidad de Valencia, 46100 Burjassot, Spain

*Corresponding author:

Nuria Paricio

Departamento de Genética, Facultad de CC Biológicas, Universidad de Valencia

Dr. Moliner 50

E-46100 Burjassot, Spain

Phone: +34-96354 3005

Fax: +34-96 3543029

E-mail: nuria.paricio@uv.es

\begin{abstract}
Abbreviations: AD, Alzheimer's disease, ER, endoplasmic reticulum; MAM, mitochondrialassociated ER membranes; MS, mass spectrometry; OS, oxidative stress; PD, Parkinson's disease; RyR, Ryanodine Receptors; ROS, reactive oxygen species; SERCA, sarco/endoplasmic reticulum $\mathrm{Ca}^{2+}$-ATPase.
\end{abstract}




\section{ABSTRACT}

$D J-1$ is a causative gene for familial Parkinson's disease (PD) with different functions, standing out its role against oxidative stress (OS). Accordingly, PD model flies harboring a mutation in the $D J-1 \beta$ gene (the Drosophila ortholog of human $D J-1$ ) show high levels of OS markers like protein carbonylation, a common post-translational modification that may alter protein function. To increase our understanding of $\mathrm{PD}$ pathogenesis as well as to discover potential therapeutic targets for pharmacological intervention, we performed a redox proteomic assay in $D J-1 \beta$ mutant flies. Among the proteins that showed increased carbonylation levels in PD model flies, we found SERCA, an endoplasmic reticulum $\mathrm{Ca}^{2+}$ channel that plays an important role in $\mathrm{Ca}^{2+}$ homeostasis. Several studies have supported the involvement of $\mathrm{Ca}^{2+}$ dyshomeostasis in PD. Interestingly, a functional link between $D J-1$ and $\mathrm{Ca}^{2+}$ homeostasis maintenance was previously reported. Thus, we decided to study the relation between SERCA activity and PD physiopathology. Our results showed that SERCA enzymatic activity is significantly reduced in $D J-1 \beta$ mutant flies, probably as a consequence of OS-induced carbonylation, as well as in a human cell PD model based on DJ-1-deficiency. Indeed, higher carbonylation levels of SERCA were also observed in DJ-1-deficient SHSY5Y neuron-like cells compared to controls. In addition, we demonstrated that SERCA activity was increased in both PD models after treatment with a specific activator of this protein, CDN1163. Consistently, CDN1163 was also able to restore PD-related phenotypes in PD model flies and to increase viability in the human cell PD model. Taken together, our results indicate that impaired SERCA activity in both familial PD models may play a role in PD physiopathology. In addition, we demonstrate that therapeutic strategies addressing SERCA activation could be beneficial to treat this disease as shown for CDN1163.

Keywords: Drosophila; SH-SY5Y cells; Parkinson's disease; SERCA; protein carbonylation; CDN1163. 


\section{INTRODUCTION}

Parkinson's disease (PD) is the second most common neurodegenerative disorder after Alzheimer's disease (AD). It is pathologically characterized by the progressive loss of dopaminergic (DA) neurons in the substantia nigra of the brain, which is responsible for the typical motor dysfunction observed in PD patients (Poewe et al., 2017). Although most PD cases are sporadic, $10 \%$ of them are monogenic forms of the disease caused by mutations in specific genes (Lill, 2016). The study of their function has been important in shedding light in the pathogenic cellular events underlying PD (Poewe et al., 2017).

One of the genes involved in PD is $P A R K 7$, which was first linked to early onset, familial forms of PD in 2003 (Bonifati et al., 2003). It encodes the DJ-1 protein to which a range of different cellular and biochemical activities have been ascribed. These include roles as a reactive oxygen species (ROS) scavenger, cysteine protease, redox-regulated chaperone and transcriptional modulator, being also involved in anti-apoptotic signaling processes and RNA regulation (Repici \& Giorgini, 2019). Despite this, how DJ-1 contributes to PD pathogenesis is still unclear (Poewe et al., 2017). Among the molecular processes underlying PD, calcium $\left(\mathrm{Ca}^{2+}\right)$ dyshomeostasis has been widely described to contribute to the appearance and progression of the disease (Alvarez et al., 2020; Zaichick et al., 2017). The first functional link between $D J-1$ and maintenance of $\mathrm{Ca}^{2+}$ homeostasis was reported in Shtifman et al. (2011), who showed that loss of $D J-1$ function in primary skeletal muscle cells obtained from $D J-1$ null mice led to an increase in cytoplasmic $\mathrm{Ca}^{2+}$. As expected, $D J-1$ mutant cells exhibited reduced $\mathrm{Ca}^{2+}$ release from the endoplasmic reticulum (ER) in response to electrical stimulation (Shtifman et al., 2011). The $\mathrm{Ca}^{2+}$ channels RyR (Ryanodine Receptors) and SERCA (sarco/ER Ca ${ }^{2+}$-ATPase) are essential for maintenance of myoplasmic $\mathrm{Ca}^{2+}$ concentration and regulation of $\mathrm{Ca}^{2+}$ release (Avila et al., 2019). However, the authors demonstrated that expression levels of these proteins were not affected in $D J-1$ mutant cells, and suggested that gene products whose expression is dependent on the DJ-1 protein could modulate the function of either RyRs or SERCA (Shtifman et al., 2011). Aberrations in the finely-tuned intraneuronal $\mathrm{Ca}^{2+}$ homeostasis may have damaging effects, leading to the emergence of brain pathology in several neurodegenerative diseases (Alvarez et al., 2020). Indeed, $\mathrm{Ca}^{2+}$ handling proteins seem to play an important role in oxidative stress (OS), the generation of free radicals as well as mitochondrial dysfunction, and alterations in their function lead to ER stress (S. W. Park et al., 2010; Zaichick et al., 2017). Thus, SERCA dysfunction has been associated to ER stress and neuron loss in neurodegenerative disorders 
(Britzolaki et al., 2020). Consistently, it was shown that SERCA overexpression and/or pharmacological activation of this protein with small allosteric specific activators may alleviate ER stress (Kang et al., 2016; Sunderhaus et al., 2019). In fact, a small molecule activator of SERCA (CDN1163) was able to increase ER $\mathrm{Ca}^{2+}$ content, to rescue neurons from ER stress-induced cell death in vitro, and to efficiently alleviate dyskinesia in the rat 6hydroxydopamine (6-OHDA) model of PD.

OS plays an important role in the development of PD (Hemmati-Dinarvand et al., 2019; Sanders \& Timothy Greenamyre, 2013). Several factors contribute to the increase of ROS levels in DA neurons, such as dopamine metabolism, mitochondrial alterations or neuroinflammation, which in turn leads to oxidative modifications of proteins, lipids and nucleic acids (Blesa et al., 2015). Protein carbonylation represents the most common type of post-translational modification that proteins may suffer either by oxidative (direct) or nonoxidative (indirect) mechanisms. OS-induced carbonyl modification of proteins has several consequences either affecting their function or even promoting its elimination (Hecker \& Wagner, 2018; Solana-Manrique et al., 2020; Suzuki et al., 2010). It has been shown that its effect on protein function depends on levels of carbonyl groups present in the molecule: while a high degree of carbonylation is correlated with protein dysfunction, moderate carbonylation may directly activate or inhibit the activities of target proteins as well as their selective proteasomal degradation (Hecker \& Wagner, 2018). Indeed, identification of oxidized proteins in cellular and animal models of several human diseases by means of redox proteomics assays has been crucial to determine cellular pathways affected in patients (Butterfield \& Dalle-donne, 2014; Ren et al., 2014; Shen et al., 2015; Sultana et al., 2013). Few redox proteomics studies have been performed so far in PD models (Bulteau et al., 2017; Chiaradia et al., 2019; Di Domenico et al., 2012; Poon et al., 2005), despite they could be useful to increase our understanding of PD pathogenesis as well as to discover potential therapeutic targets for pharmacological intervention.

In this scenario, the present work seeks to identify the target proteins of OS in a Drosophila PD model based on inactivation of $D J-1 \beta$, the fly ortholog of human $D J-1$ (Lavara-Culebras \& Paricio, 2007; Park et al., 2005). It was previously shown that 15-day-old $D J-1 \beta$ mutants exhibited increased ROS and protein carbonylation levels when compared to control flies of the same age (Casani et al., 2013; Lavara-Culebras et al., 2010). To achieve this, we performed redox proteomics analyses in PD model and control flies, being able to identify proteins differently carbonylated in $D J-1 \beta$ mutants that could be involved in several 
cellular processes associated with the disease. Among those that exhibited increased carbonylation levels in PD model flies we found SERCA, a protein encoded by the Drosophila Ca-P60A gene (Sanyal et al., 2005) also known as $A S E R C A$. Our results demonstrate that SERCA enzymatic activity is significantly reduced in $D J-1 \beta$ mutant flies as well as in DJ-1-deficient SH-SY5Y neuron-like cells compared to controls. These results indicate that SERCA carbonylation leads to its inactivation in those PD models, as found in mammals (Žižková et al., 2014, 2018). Furthermore, we show that activation of SERCA with a specific allosteric activator of this protein (CDN1163) is capable to suppress PD-related phenotypes in fly and human cell models based on $D J-1$ deficiency. Therefore, our results support the crucial role of SERCA activity in PD pathology, and demonstrate that targeting SERCA activation is a promising strategy to develop disease-modifying therapeutics for PD.

\section{MATERIALS AND METHODS}

\section{Drosophila strains}

The stocks used in this work were: $y, w$ (Bloomington Drosophila $\underline{\text { Stock }}$ Center \#6598: $y^{1}, w^{1118}$ ), $w$; $D J-1 \beta^{e x 54}$ (hereafter called $D J-1 \beta$; Park et al. 2005), arm-GAL4 (BDSC \#1560: $P\{G A L 4-a r m . S\} 11)$, UAS-iRdSERCA (Vienna Drosophila Research Center \#3017: $w^{1118}$; $P\{G D 1508\}$ v3017). All stocks and crosses were cultured on standard Drosophila food at $25^{\circ} \mathrm{C}$, unless otherwise indicated. The $y, w$ line was used as wild-type control in experiments with the $D J-1 \beta$ strain. For RNAi experiments, the arm-GAL4 driver line was crossed with UAS-iRdSERCA to ubiquitously downregulate $d S E R C A$ expression. Progeny of this cross is referred to as $i R d S E R C A$. In these experiment, progeny of crosses between $y, w$ and arm-GAL4 flies was used as control.

\section{Redox proteomics assay}

Carbonylated protein derivatization

Groups of fifty 15-day-old female flies were homogenized in extraction buffer [ $8 \mathrm{M}$ urea, 25 $\mathrm{mM}$ Tris pH 8, Halt Protease Inhibitor Cocktail (Thermo Scientific)] with a steel bead in a TissueLyser LT (Qiagen) for $5 \mathrm{~min}$ at $50 \mathrm{~Hz}$ at $4^{\circ} \mathrm{C}$. Fly extracts were centrifuged three times at $9000 \mathrm{~g}$ for $10 \mathrm{~min}$ at $4^{\circ} \mathrm{C}$. After centrifugation, supernatant was collected and proteins were 
quantified using a NanoDrop 2000 spectrophotometer (Thermo Scientific). For protein precipitation, the 2-D Clean-Up Kit (GE Healthcare) was used following manufacturer's instructions. Subsequently, $300 \mu \mathrm{g}$ of protein were derivatized using the BodipyFL hydrazide (Invitrogen) as described in Tamarit et al. (2012).

\section{$\underline{2 \mathrm{D} \text { immunoblotting }}$}

Derivatized-protein samples were analysed by two-dimensional (2D) gel electrophoresis using Immobiline ${ }^{\circledR}$ DryStrips pH 3-11 (IPG) non-linear (NL) $24 \mathrm{~cm}$ (GE Healthcare) for isoelectric focusing (IEF) as the first dimension and SDS-PAGE separation as the second dimension. Samples were supplemented with $65 \mathrm{mM}$ DTT and 1\% ampholytes (Healthcare GE). IPG strips were rehydrated overnight with DeStreak ${ }^{\mathrm{TM}}$ Rehydration Solution (GE Healthcare) and 1\% (v/v) ampholytes ( $\mathrm{pH}$ 3-11 NL; GE Healthcare) following manufacturer's instructions. IEF conditions were performed with the following voltage program: $300 \mathrm{~V}$ for 4 $\mathrm{h}$, linear ramp to $1000 \mathrm{~V}$ over $6 \mathrm{~h}$, linear ramp to $8000 \mathrm{~V}$ over $3 \mathrm{~h}$, then 8000 constant for a total focusing time of $28000 \mathrm{Vh}$ at $20^{\circ} \mathrm{C}$. After IEF, the IPG strips were reduced for $15 \mathrm{~min}$ with 2\% (w/v) DTT in $50 \mathrm{mM}$ Tris, $6 \mathrm{M}$ urea, 30\% (v/v) glycerol, 2\% (w/v) SDS, and subsequently for $15 \mathrm{~min}$ in the same buffer containing $2.5 \%(\mathrm{w} / \mathrm{v})$ iodoacetamine instead of DTT. In the second dimension, proteins were separated on $12.5 \%(\mathrm{v} / \mathrm{v})$ acrylamide gels of 25 $\mathrm{cm} \times 21 \mathrm{~cm} \times 1 \mathrm{~mm}$ using an Ettan DALTsix electrophoresis unit (GE Healthcare). The SDSPAGE was first run at a current of $2 \mathrm{~W} /$ gel for $1 \mathrm{~h}$ and then at a constant current of $15 \mathrm{~W} / \mathrm{gel}$ for $5 \mathrm{~h}$. After gel electrophoresis, total protein content in the gels was stained with $\mathrm{SYPRO}^{\circledR}$ Ruby Protein Stain (Invitrogen) following manufacturer's instructions. Stained gels were imaged using a TyphoonTM 9400 Variable Mode Imager (GE Healthcare) using the filter that adjusted to an emission wavelength of $510 \mathrm{~nm}$ and $610 \mathrm{~nm}$ for the BODIPY dye and for the SYPRO $^{\circledR}$ Ruby dye, respectively. Samespots software version 5.0 (TotalLab) was used to compare protein carbonylation between control and $D J-1 \beta$ flies. Proteins equally expressed in both genotypes whose carbonylation levels were significantly increased $(\mathrm{P}<0.05)$ in $\mathrm{PD}$ model flies were selected for subsequent identification.

\section{Mass spectrometry}

Gels were silver stained by using the PlusOne Silver Staining Kit (protein, GE Healthcare) to excise the selected spots following manufacturer's instructions. The spots were digested with sequencing grade trypsin (Promega) as described (Shevchenko et al., 1996). Digestion was stopped with TFA $(1 \%(\mathrm{v} / \mathrm{v})$ final concentration) and the digested peptides were concentrated 
to $7 \mu \mathrm{L}$. A BSA plug was analysed in the same way to control the digestion process. The resulting mixtures were analyzed by tandem mass spectrometry (MS/MS) in a 5800 MALDI TOFTOF (ABSciex) in positive reflectron mode (3000 shots every position). Five of the most intense precursors (according to the threshold criteria: minimum signal-to-noise: 10, minimum cluster area: 500, maximum precursor gap: 200 ppm, maximum fraction gap: 4) were selected for every position for the MS/MS analysis. MS/MS data was acquired using the default $1 \mathrm{kV}$ MS/MS method. The MS/MS information was sent to MASCOT via the Protein Pilot (ABSciex). Database search was performed on Unigen database. Searches were done with tryptic specificity allowing one missed cleavage and a tolerance on the mass measurement of $100 \mathrm{ppm}$ in MS mode and 0.8 Da in MSMS mode. Carbamidomethylation of Cys was used as a fixed modification and oxidation of Met and deamidation of Asn and Gln as variable modifications.

For the spots that could not be identified by MS/MS, a liquid chromatography and tandem mass spectrometry (LC-MS/MS) analysis was performed. $5 \mu 1$ of every sample (except the

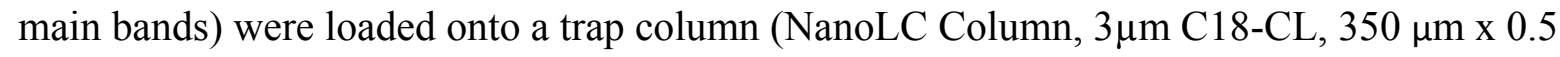
$\mathrm{mm}$; Eksigen) and desalted with $0.1 \%(\mathrm{v} / \mathrm{v}) \mathrm{TFA}$ at $3 \mu \mathrm{l} / \mathrm{min}$ during $5 \mathrm{~min}$. The peptides were then loaded onto an analytical column (LC Column, $3 \mu \mathrm{m}$ C18-CL, $75 \mu \mathrm{m}$ x $12 \mathrm{~cm}$, Nikkyo) equilibrated in $5 \%(\mathrm{v} / \mathrm{v})$ acetonitrile $0.1 \%(\mathrm{v} / \mathrm{v})$ formic acid. Elution was carried out with a linear gradient of $5-45 \% \mathrm{~B}$ in A for $15 \mathrm{~min}(\mathrm{~A}: 0.1 \%(\mathrm{v} / \mathrm{v})$ formic acid; B: $0.1 \%(\mathrm{v} / \mathrm{v})$ formic acid in acetonitrile) at a flow rate of $300 \mathrm{nl} / \mathrm{min}$. Peptides were analysed in a mass spectrometer nanoESI qQTOF (5600 TripleTOF, ABSCIEX).

The tripleTOF was operated in information-dependent acquisition mode, in which a $0.25-\mathrm{s}$ TOF MS scan from 350-1250 m/z was performed, followed by 0.05 -s product ion scans from $100-1500 \mathrm{~m} / \mathrm{z}$ on the 50 most intense $2-5$ charged ions. The LC-MS/MS information was sent to ProteinPilot v4.5 search engine (ABSciex). Data obtained from the sample were analysed combined for database search. ProteinPilot default parameters were used to generate peak list directly from 5600 TripleTof .wiff files. The Paragon algorithm of ProteinPilot was used to search NCBI protein database with the following parameters: trypsin specificity, iodoacetamide cys-alkylation, taxonomy restricted to Drosophila melanogaster, and the search effort set to rapid. To avoid using the same spectral evidence in more than one protein, the identified proteins were grouped based on MS/MS spectra by the Protein-Pilot Progroup algorithm. Thus, proteins sharing MS/MS spectra were grouped, regardless of the peptide sequence assigned. The protein within each group that can explain more spectral data with confidence was shown as the primary protein of the group. 


\section{Climbing assays}

Locomotor ability of flies was analyzed by means of climbing assays as previously described in Sanz et al. (2017). The experiments were carried out three times and the climbing ability of mutant flies and their corresponding controls was determined as the average of the height reached by each fly after $10 \mathrm{~s}$.

\section{Cell culture and drug treatment}

SH-SY5Y neuroblastoma control cells ( $p L K O .1)$ and DJ-1-deficient cells (Sanz et al., 2017) were maintained in a selective growth medium consisting of Dulbecco's Modified Eagle Medium/Nutrient Mixture F-12 (DMEM/F-12) (Labclinics) supplemented with $2 \mu \mathrm{g} / \mathrm{ml}$ puromycin (Labclinics), 10\% (v/v) fetal bovine serum (FBS) (Labclinics) and $100 \mathrm{mg} / \mathrm{ml}$ penicillin/streptomycin (Labclinics) at $37^{\circ} \mathrm{C}$ and $5 \% \mathrm{CO}_{2}$.

Cell viability assays in $D J$-1-deficient cells treated with different concentrations of CDN1163 (Sigma-Aldrich) were performed with MTT (3-(4, 5-dimethylthiazol-2-yl)-2-5diphenyltetrazolium bromide) (Sigma-Aldrich) as described in Sanz et al. (2017), with slight modifications. Briefly, $D J$-1-deficient cells were seeded in a 96-well plate at a density of $1.8 \times 10^{4}$ cells/well and incubated for $24 \mathrm{~h}$ with different concentrations of CDN1163 in the range $1-50 \mu \mathrm{M}$, or with $0.1 \%$ dimethyl sulfoxide (DMSO) as vehicle. Subsequently they were incubated with $100 \mu \mathrm{M} \mathrm{H}_{2} \mathrm{O}_{2}$ for $3 \mathrm{~h}$.

\section{SERCA activity assay}

To obtain protein extracts from adult flies of different genotypes, 20 female flies were homogenized in Homogenization buffer [250 mM sucrose, 5 mM HEPES pH 7, 1 mM PMSF, Halt Protease Inhibitor Cocktail (Thermo Scientific)] with a steel bead in a TissueLyser LT (Qiagen) for $5 \mathrm{~min}$ at $50 \mathrm{~Hz}$. Fly extracts were centrifuged at $9000 \mathrm{~g}$ for $8 \mathrm{~min}$ at $4^{\circ} \mathrm{C}$. After centrifugation supernatant was collected. Protein extracts from $D J$-1-deficient and control SH-SY5Y cells were obtained from aliquots of $3 \times 10^{6}$ cells. To do this, cells were lifted with trypsin and harvested in complete DMEM-F12 medium, centrifuged at 300g for $5 \mathrm{~min}$, washed with $1 \%$ PBS buffer at $4{ }^{\circ} \mathrm{C}$ and resuspended in Homogenization buffer $[250 \mathrm{mM}$ sucrose, 5 mM HEPES pH 7, 1 mM PMSF, Halt Protease Inhibitor Cocktail (Thermo Scientific)]. Cell suspensions were subjected to three successive cycles of freezing in liquid $\mathrm{N}_{2}$, thawing on ice and vortexing. Lysates were centrifuged at $15.000 \mathrm{~g}$ for $10 \mathrm{~min}$ at $4{ }^{\circ} \mathrm{C}$ and supernatant was collected. Supernatants containing fly and cell lysates were quantified with 
Pierce ${ }^{\mathrm{TM}}$ BCA Protein Assay Kit (Thermo Scientific) following manufacturer's instructions. SERCA activity was measured by spectrophotometric assay using an enzyme-coupled system as described in Moraru et al. (2017). Previously, the SERCA activity assay was validated in iRdSERCA mutant flies, in which the expression of the gene encoding this protein is reduced. All the assays were performed in triplicate.

\section{RT-qPCR analyses}

Total RNA from ten 15-day-old $D J-1 \beta, i R d S E R C A$ or control flies $(y, w$ or arm-GAL4/+, depending on the experiment) and from aliquots of $3 \times 10^{6} \mathrm{DJ}-1$ mutant and control cells was extracted and reverse transcribed as described in Solana-Manrique et al. (2020).

For the RT-qPCR reactions, the following pairs of primers were used: Drosophila dSERCA direct primer (5'-3'); Drosophila dSERCA reverse primer (5'-3'); Drosophila Tubulin direct primer (5'-GTATCTCTATCCATGTTGGTCAGG-3'); Drosophila Tubulin reverse primer (5'-AGACGGCATCTG GCCATCG-3'); Homo sapiens ATP2A1 direct primer (5' -3'); Homo sapiens ATP2A1 reverse primer (5'-3'); Homo sapiens ATP2A2 direct primer (5'-3'); Homo sapiens ATP2A2 reverse primer (5'-3'); Homo sapiens Tubulin direct primer (5'GCCGAGATCACCAATGCCT-3'); Homo sapiens Tubulin reverse primer (5'TCACACTTGACCATTTGATTGGC-3').

\section{SERCA immunoprecipitation and post-Western blot derivatizarion}

To confirm the redox proteomic assay results, carbonylation levels of SERCA were detected by immunoprecipitation and post-Western blot derivatization in control and $D J$-1-deficient cells. For protein extraction, aliquots of $3 \times 10^{6}$ cells of mutant and control cells were homogenized in cell lysis buffer [ $25 \mathrm{mM}$ Tris pH8, 0.05\% (w/v) SDS, $75 \mathrm{mM} \mathrm{NaCl}, 0.5 \%$ (v/v) Triton X-100, 0.25\% (w/v) sodium deoxycholate, $100 \mathrm{mM} \mathrm{NaF}, 20 \mathrm{mM} \mathrm{Na}_{4} \mathrm{P}_{2} \mathrm{O}_{7}, 1 \mathrm{mM}$ PMSF, Halt Protease Inhibitor Cocktail (Thermo Scientific)] with brief sonication. Extracts were centrifuged at $15.000 \mathrm{~g}$ for $10 \mathrm{~min}$ at $4^{\circ} \mathrm{C}$ and supernatants were collected and quantified with Pierce ${ }^{\mathrm{TM}}$ BCA Protein Assay Kit (Thermo Scientific) following manufacturer's instructions. Protein samples $(200 \mu \mathrm{g})$ were incubated with anti-SERCA antibody (CaF2-5D2, Developmental Studies Hybridoma Bank) for $1 \mathrm{~h}$ at $4{ }^{\circ} \mathrm{C}$ with gentle shaking. Pierce ${ }^{\mathrm{TM}}$ Protein A Agarose (Thermo Scientific) beads were added, and the mixture was incubated for $4 \mathrm{~h}$ at $4{ }^{\circ} \mathrm{C}$ with gentle shaking. After incubation, beads were centrifuged and washed three times with cells lysis buffer. Then, beads were resuspended in SDS loading buffer [62.5 mM Tris pH 6.8, 2\% (w/v) SDS, 10\% (v/v) glycerol, $50 \mathrm{mM} \mathrm{DTT,} 0.01 \%(\mathrm{p} / \mathrm{v})$ bromophenol blue] 
and boiled for $5 \mathrm{~min}$. Proteins bound to beads were separated by SDS-PAGE and transferred to nitrocellulose membranes, which were subsequently derivatized as described in Feng et al. (2017). Carbonylation levels were detected by incubating the membranes with anti-DNP (1:250, Sigma-Aldrich) overnight at $4^{\circ} \mathrm{C}$. Blots were then washed and incubated with the goat anti-rabbit IgG/HRP conjugate (1:5000, Sigma-Aldrich). The signal was detected with a Pierce $^{\mathrm{TM}}$ ECL detection kit (Thermo Scientific) and captured using ImageQuant LAS4000. Images were analyzed with ImageJ software (NIH).

\section{CDN1163 treatments in Drosophila}

Flies were cultured on standard Drosophila food containing 0.1\% DMSO for untreated control experiments, or in the same medium supplemented with a final concentration of 50 $\mu \mathrm{M}$ CDN1163. Ten males and 20 females of $y, w$ or $D J-1 \beta$ flies were crossed in each vial with or without compound and maintained at $25{ }^{\circ} \mathrm{C}$. For climbing assays, freshly eclosed flies were transferred to new vials with the compounds and the climbing assay was carried out 5 days after eclosion. For enzymatic assays, freshly eclosed flies were transferred to new vials with or without the compounds every two days for 15 days. After this time, 15-day-old flies were frozen in liquid $\mathrm{N}_{2}$ and stored at $-80^{\circ} \mathrm{C}$.

\section{Quantification of protein carbonyl group formation and $\mathrm{H}_{2} \mathrm{O}_{2}$ levels}

Protein carbonyl groups were measured in 5-day-old fly extracts using 2,4dinitrophenylhydrazine (DNPH) derivatization in 96-well plates (Greiner 96 well plate, polypropylene) as described in Sanz et al. (2017). $\mathrm{H}_{2} \mathrm{O}_{2}$ levels were measured using the Amplex $\mathrm{H}_{2} \mathrm{O}_{2}$ Red Kit (Invitrogen) in 5-day-old fly extracts with as described in Sanz et al., (2017). All experiments were carried out using three biological replicates and three technical replicates for each sample.

\section{Statistical analysis}

In all cases, data are expressed as means \pm standard deviation (s.d.). The significance of differences between means was assessed using t-test. Differences were considered significant when $* P<0.05$.

\section{RESULTS}




\section{Carbonylation protein pattern in $D J-1 \beta$ mutant flies}

Previous studies performed in 15-day-old $D J-1 \beta$ mutants showed that protein carbonylation levels were significantly increased in such flies when compared to controls of the same age (Casani et al., 2013). In order to identify specific proteins that were most susceptible to oxidative damage in PD model flies, we undertook redox proteomic analyses in 15-day-old $D J-1 \beta$ mutants and $y, w$ control flies. To our knowledge, this is the first redox proteomics assay performed in a Drosophila PD model. Figure 1 shows representative 2D Sypro Rubystained gels for total protein content (Fig. 1A) and the corresponding Bodipy staining (Fig. 1B) for oxidized proteins obtained in these experiments. The redox proteomics analyses led to identify 53 spots corresponding to differently carbonylated proteins with equivalent expression levels. Specifically, 31 of them showed increased levels and 22 showed reduced levels in 15-day-old $D J-1 \beta$ mutants compared to control flies of the same age. Some of the differentially carbonylated proteins, evidenced by Bodipy staining, were subsequently characterized by proteomic procedures (see Materials and Methods section for details). We specifically focused on those spots corresponding to proteins with increased carbonylation levels in PD model flies, from which twelve were selected for mass spectrometry (MS) identification (see Materials and Methods). Table 1 shows the proteins identified in these experiments, the genes encoding them and the fold increase in oxidation of each protein in $D J-1 \beta$ mutants compared to control flies, which ranges from 1.4 to 2.8 . The functions of the identified proteins are diverse (see Table S1). Two of them, enolase (Eno) and phosphofructokinase (Pfk), are glycolytic enzymes and were shown to present enhanced activity in PD model flies compared to controls (Solana-Manrique et al., 2020). Other proteins identified were: voltage-dependent anion-selective channel (VDAC), , actin, vitellogenin-2 and 3, tyrosyl-tRNA synthethase, myosin heavy chain, V-type proton ATPase catalytic subunit A isoform 2, arginine kinase and citrate synthase. Interestingly, this is the first study in which some of these proteins are shown to be specifically carbonylated in an animal model of familial PD.

Among the proteins identified, SERCA (EC 7.2.2.10) is an ion channel associated to $\mathrm{Ca}^{2+}$ homeostasis and located in the ER. It balances calcium between the ER and the cytosol by pumping $\mathrm{Ca}^{2+}$ into the ER in order to ensure proper protein folding and chaperone function (Britzolaki et al., 2020, Sunderhaus et al., 2019). Although its exact role in the central nervous system is not clear yet, it is known that SERCA-mediated $\mathrm{Ca}^{2+}$ dyshomeostasis is associated with neuropathological conditions (Alvarez et al., 2020; Britzolaki et al., 2020). Several 
studies indicate that inhibition of SERCA function is related to neurodegeneration (Britzolaki et al., 2020; Sunderhaus et al., 2019), thus suggesting that this could be a major cause of PD (Alvarez et al., 2020). Therefore, we suspected that alterations of SERCA function caused by high carbonylation levels could be contributing to PD-related phenotypes in $D J-1 \beta$ mutant flies as well as to PD physiopathology by affecting $\mathrm{Ca}^{2+}$ homeostasis.

\section{SERCA activity is reduced in $D J-1 \beta$ mutants}

As mentioned above, one of the proteins that exhibited increased carbonylation levels in 15day-old $D J-1 \beta$ mutants compared to control flies of the same age was the SERCA $\mathrm{Ca}^{2+}$ pump. To determine the consequences of such posttranslational modification on SERCA function, we decided to measure its activity in $D J-1 \beta$ mutants by using a protocol already tested in Drosophila (Moraru et al., 2017). We first validated the SERCA activity assay in protein extracts from $i R d S E R C A$ flies, in which the expression of the $d S E R C A$ gene was ubiquitously downregulated with the arm-GAL4 driver. As expected, SERCA activity was significantly reduced in mutant flies compared to controls (Fig. 2A), due to a decrease in $A S E R C A$ expression levels in such flies (Fig. 2B). Subsequently, we analyzed SERCA activity in 15day-old $D J-1 \beta$ mutants and $y, w$ control flies using the same assay. Our results showed that SERCA activity was significantly reduced in PD model flies compared to controls (Fig. 2A), despite that $d S E R C A$ expression levels were equivalent in both fly strains (Fig. 2B).

Consistently, we found that 15-day-old $i R d S E R C A$ mutants showed phenotypes similar to those exhibited by DJ-1 $\beta$ mutants (Lavara-Culebras \& Paricio, 2007). Hence, iRdSERCA mutant flies displayed motor impairments, reflected by a reduced climbing ability, and also a decreased lifespan when compared to control flies (Fig. S1). These results are in agreement with previous reports in which other $A S E R C A$ mutants were analyzed (Kaneko et al., 2014; Sanyal et al., 2005). Taken together, our results support the existence of a functional link between $D J-1$ and $\mathrm{Ca}^{2+}$ homeostasis maintenance, as previously suggested in mice (Shtifman et al., 2011), and indicate that loss of $D J-1 \beta$ function may have a direct impact on the activity of this $\mathrm{Ca}^{2+}$ pump probably due to high ROS levels. 
To confirm the results obtained in Drosophila, we analyzed SERCA activity in an in vitro human cell PD model based on DJ-1-deficiency (Sanz et al., 2017). We and others already showed that those cells were more susceptible than control cells to OS-induced cell death (Gao et al. 2011; Sanz et al. 2017; Solana-Manrique et al. 2020; Wang et al. 2011). Therefore, SERCA activity was determined under OS conditions induced with $50 \mu \mathrm{M} \mathrm{H}_{2} \mathrm{O}_{2}$, a concentration that significantly decreased viability of $D J$-1-deficient cells compared to controls but in which enough cells could be harvested (Solana-Manrique et al., 2020). Our results showed that SERCA activity was significantly reduced in DJ-1-deficient cells (Fig. 3A). To exclude the possibility that variations in SERCA activity between $D J$-1-deficient and control cells were reflecting differences in gene expression levels, we performed RT-qPCR assays. Using the sequence of the Drosophila dSERCA gene (CG3725) as a query, we found different SERCA orthologs in humans. Among them, we selected those genes that are significantly expressed in SH-SY5Y cells according to the Human Protein Atlas (Uhlén et al., 2010, 2015) such as $A T P 2 A 1$ and $A T P 2 A 2$, which encode the SERCA1 and SERCA2 isoforms, respectively. No significant differences were detected in $A T P 2 A 1$ and $A T P 2 A 2$ expression levels between $D J$-1-deficient and control cells (Fig. 3B). These results are consistent with those found in skeletal muscle of $D J-1$ null mice in which no significant alterations in the steady-state expression levels of the SERCA1 protein were found (Shtifman et al., 2011). To determine whether reduction of SERCA activity could be associated to its oxidative modification, we decided to analyze SERCA carbonylation levels in PD model and control cells. To do so, we performed SERCA immunoprecipitation with an anti-SERCA1 antibody and post-Western blot derivatization of protein extracts using an anti-DNP antibody. As shown in Fig. 3C, the SERCA protein was equally expressed in both cell lines but showed significantly increased carbonylation levels in $D J$-1-deficient cells. These results confirmed that SERCA activity was reduced in the human cell PD model based on $D J-1$ deficiency due to an increase in its carbonylation levels, and validated the results obtained in the redox proteomics assays with $D J-1 \beta$ mutant flies.

\section{The SERCA activator CDN1163 suppresses phenotypes in DJ-1ß mutant flies and DJ-1- deficient cells}

Dysregulation of $\mathrm{Ca}^{2+}$ homeostasis and ER stress have been linked to neurodegeneration and to the development of neurodegenerative diseases, such as PD (Britzolaki et al., 2020; Dahl, 2017; Rahate et al., 2020). The SERCA pump is a protein whose main function is to transport 
$\mathrm{Ca}^{2+}$ into the ER, hence maintaining physiological cytoplasmic $\mathrm{Ca}^{2+}$ levels, and its activation has been associated to an alleviation of ER stress (Dahl, 2017; Qaisar et al., 2019). Therefore, we decided to test if an increase of SERCA activity could attenuate phenotypes in our fly and human cell models of PD by using the compound CDN1163 (Dahl, 2017). CDN1163 is a quinolone-amide that acts as an allosteric activator of SERCA, directly binding to this protein. First, we tested the effect of CDN1163 in PD-related phenotypes exhibited by $D J-1 \beta$ mutants, such as reduced locomotor activity as well as elevated ROS and protein carbonylation levels (Casani et al., 2013; Lavara-Culebras et al., 2010; Lavara-Culebras \& Paricio, 2007). Our results showed that PD model flies treated with CDN1163 during development and 5 days after eclosion displayed a significant improvement of their locomotor activity when compared to individuals treated with vehicle (DMSO) (Fig. 4A). A significant reduction in protein carbonylation levels was also observed in $D J-1 \beta$ mutant flies treated with CDN1163 (Fig. 4B). However, no differences in $\mathrm{H}_{2} \mathrm{O}_{2}$ levels, a component of the total ROS pool (Casani et al., 2013; Sanz et al., 2017), were detected (Fig. 4C). To determine whether the suppression of those phenotypes was due to SERCA activation, we tested the activity of this protein in $D J-1 \beta$ mutant flies treated with CDN1163 by using the specific protocol mentioned above. Our results showed that SERCA activity was significantly increased in those flies when compared to vehicle-treated flies (Fig. 4D), thus indicating that PD-related phenotypes in $D J-1 \beta$ mutants could be caused in part by dysregulation of $\mathrm{Ca}^{2+}$ homeostasis. Although Drosophila is a valuable organism that allows to test the effect of compounds in living organisms, those shown to be beneficial in flies should be validated in mammalian models (Solana-Manrique et al., 2019). Thus, to determine the translatability of the results obtained in PD model flies, we performed cell viability assays in $D J$-1-deficient cells pretreated with five concentrations of CDN1163 (in a range 1-50 $\mu \mathrm{M}$ ) in OS conditions (see Materials and Methods section). Our results showed that treatment with CDN1163 exerted a protective effect against OS-induced cell death in DJ-1-deficient cells in a dosage-dependent manner (Fig. 5A). Subsequently, we performed the SERCA activity assay in cells pretreated with $5 \mu \mathrm{M}$ CDN1163, the most effective concentration in suppressing OS-induced cell death, to determine if SERCA activity was increased in treated cells as shown in the Drosophila PD model. We found that cells pretreated with CDN1163 also exhibited a significant increase in SERCA activity compared to vehicle-treated cells (Fig. 5B). In summary, our results confirmed that CDN1163 exerts a protective role in PD models based on DJ-1 deficiency through SERCA inactivation. These results indicate that CDN1163 could be a potential therapeutic compound for PD, and confirms SERCA as a therapeutic target for pharmacological intervention in PD patients. 


\section{DISCUSSION}

In order to obtain a better understanding of how $D J-1$ may contribute to PD pathophysiology, we carried out a redox proteomic assay in a Drosophila PD model based on $D J-1 \beta$ inactivation. This study led us to identify oxidatively modified proteins in $D J-1 \beta$ mutants whose function could be altered in such flies. We specifically focused on the SERCA calcium pump, a protein that plays a central role in $\mathrm{Ca}^{2+}$ homeostasis (Britzolaki et al., 2020). The SERCA protein showed increased carbonylation levels and impaired activity in $D J-1 \beta$ mutants compared to control flies. These results were confirmed in DJ-1-deficient SH-SY5Y neuron-like cells. Thus, we concluded that loss of $D J-1$ function has a direct impact on the activity of this $\mathrm{Ca}^{2+}$ pump. In addition, SERCA activation using CDN1163 was shown to rescue PD-related phenotypes in both models. Taken together, our results demonstrated that SERCA dysfunction could be relevant for PD pathophysiology, thereby constituting a convincing therapeutic target for this disease, and that CDN1163 might play an important therapeutic role in PD.

To our knowledge, this is the first redox proteomic assay performed in a Drosophila PD model. OS-induced carbonyl modification of proteins has several consequences either affecting their function (activating or inhibiting them) or even promoting its elimination (Hecker \& Wagner, 2018). We have recently demonstrated that the glycolytic enzymes Eno and Pfk, also identified in our redox proteomics assay (see Table 1), showed increased activity in the Drosophila and human cell PD models based on DJ-1 deficiency (SolanaManrique et al., 2020). In addition, among the proteins showing increased carbonylation levels in $D J-1 \beta$ mutants we found actin, which is one of the most susceptible proteins to this modification under OS conditions (Castro et al., 2013). In the present study, we have focused on the SERCA protein, a $\mathrm{Ca}^{2+}$ pump located in the ER and ubiquitously expressed in eukaryotic cells (Primeau et al., 2018). SERCA pumps are a group of proteins that regulate cytoplasmic $\mathrm{Ca}^{2+}$ levels by facilitating the transport of $\mathrm{Ca}^{2+}$ into the ER, the most important $\mathrm{Ca}^{2+}$-storage organelle (Britzolaki et al., 2020; Lam \& Galione, 2013; Rahate et al., 2020). We demonstrated that SERCA activity is impaired in DJ-1-deficient flies and human cells probably due to its carbonyl modification. This modification could be the consequence of increased ROS production in absence of $D J-1$ function, as shown in $D J-1 \beta$ mutant flies (Casani et al., 2013; Lavara-Culebras et al., 2010). However, previous studies have 
demonstrated that SERCA function can be also inhibited through carbonylation by methylglyoxal (Žižková et al., 2018), a by-product of glycolysis shown to accumulate when the glycolytic pathway is overactivated (Allaman et al., 2015). Considering that glycolysis is enhanced in PD models based on $D J-1$ deficiency, in order to counteract mitochondrial dysfunction and energetic deficiency (Requejo-Aguilar et al., 2015; Solana-Manrique et al., 2020), high levels of SERCA carbonylation in the models could be also due to methylglyoxal accumulation. In any case, SERCA dysfunction may lead to an increase in cytoplasmic $\mathrm{Ca}^{2+}$ levels thus promoting ER stress-induced apoptosis (Lin et al., 2008). Consistently, increased $\left[\mathrm{Ca}^{2+}\right]$ cytoplasmic levels were detected in skeletal muscle cells of $D J-1$ null mice (Shtifman et al., 2011). It has been shown that $\mathrm{Ca}^{2+}$ also plays an important role in coordinating organelle networks, such as mitochondria associated membranes (MAM), a major point of $\mathrm{Ca}^{2+}$ entrance from the ER to the mitochondria (Chernorudskiy \& Zito, 2017; Erpapazoglou et al., 2017; Zaichick et al., 2017). This entrance is mediated by a protein complex composed of VDAC, $\mathrm{IP}_{3} \mathrm{R}$ and Grp75 (Erpapazoglou et al., 2017). Moreover, it has been demonstrated that DJ-1 directly interacts with that protein complex, probably leading to its assembly (Basso et al., 2020; Liu et al., 2019). Besides, $D J-1$ deficiency was shown to produce a decrease in MAMs number (Basso et al., 2020; Liu et al., 2019). Interestingly, we found that VDAC carbonylation levels were also increased in $D J-1 \beta$ mutant flies in the redox proteomics assay (see Table 1). Therefore, loss of $D J-1$ function might lead to an impairment of $\mathrm{Ca}^{2+}$ influx from the ER to the mitochondria through MAMs either by interfering with the formation of the protein complex or by leading oxidative modification of VDAC. However, further studies will be required to confirm these hypotheses. Taken together, our results suggest that high OS levels may directly lead to alteration in $\mathrm{Ca}^{2+}$ homeostasis in PD models based on $D J-1$ deficiency, probably as a consequence of oxidative modification of proteins essential for this process.

Considering the impact of impaired $\mathrm{Ca}^{2+}$ homeostasis in PD, compounds addressed to reduce cytoplasmic $\mathrm{Ca}^{2+}$ have been suggested to be potential candidate therapeutics (Zaichick et al., 2017). In this study, we have tested the efficacy of CDN1163, a specific SERCA activator, in suppressing phenotypes in PD models based on $D J-1$ deficiency. Our work demonstrates that CDN116 has beneficial effects in both Drosophila and human cell familial PD models, thus supporting a previous work in which CDN1163 improved motor defects in 6-OHDA-lesioned rats, an idiopathic PD model (Dahl, 2017). Defects in SERCA activity are not only found in PD. AD, diabetes, muscular dystrophies or aging are pathologies in which 
SERCA activity is also decreased. Since these diseases are also characterized by elevated ROS levels, it is very likely that OS-induced carbonyl modification might be responsible of SERCA dysfunction (Qaisar et al., 2019; Rahate et al., 2020). Indeed, pharmacological restoration of SERCA with CDN1163 prevents OS-mediated muscle impairment in Sod1 ${ }^{-}$ mice (Qaisar et al., 2019). In this context, the consequences of SERCA activation have been also evaluated in several models of these diseases. For instance, CDN1163 lowered fasting blood glucose and enhanced glucose tolerance in a mouse model of type 2 diabetes (Kang et al., 2016). Moreover, this compound also increased viability of rat neuronal cells and improved memory and motor performance in a mouse AD model (Krajnak \& Dahl, 2018). Besides, BGP-15, a pharmacological inducer of Hsp72, increased SERCA activity under conditions of cellular stress and was found to be effective in Duchenne muscular dystrophy (Gehrig et al., 2012). Finally, overexpression of SERCA2b in the liver of obese mice was able to reduce ER stress, one of PD-related phenotypes (Park et al., 2010). Taken together, our results and those obtained in previous studies support the hypothesis that targeting $\mathrm{Ca}^{2+}$ dyshomeostasis, and more specifically activating SERCA activity, is a powerful therapeutic approach for PD as well as for other neurodegenerative diseases characterized by increased OS.

In summary, we demonstrated that SERCA activity is reduced in $D J-1$ mutant flies and human cells as a consequence of OS-induced carbonylation and, accordingly, treatments with the specific SERCA activator CDN1163 might have beneficial effects in PD. Hence, this supports the idea of using drugs addressed to restore $\mathrm{Ca}^{2+}$ homeostasis as pharmacological therapies for PD. It should be mentioned that an over-oxidized and inactive form of the DJ-1 protein has been found in brains of idiopathic PD patients (Repici \& Giorgini, 2019). Therefore, it would be interesting to determine whether SERCA activity is not only altered by oxidative modification in PD models based on $D J-1$ deficiency but also in other models of familial and idiopathic PD.

\section{ACKNOWLEDGMENTS}

We are grateful to Dr. Jongkyeong Chung, the Bloomington Drosophila Stock Center and the Vienna Drosophila Research Center for providing fly stocks. The CaF2-5D2 monoclonal antibody developed by Johns Hopkins School of Medicine was obtained from the 
Developmental Studies Hybridoma Bank, created by the NICHD of the NIH and maintained at The University of Iowa, Department of Biology, Iowa City, IA 52242.

\section{FUNDING}

This work was supported by the University of Valencia [grant number UV-INV-AE17702300 to N.P.]. The proteomic analysis was performed in the proteomics facility of SCSIE University of Valencia. This proteomics laboratory is a member of Proteored, PRB3 and is supported by grant PT17/0019, of the PE I+D+i 2013-2016, funded by ISCIII and ERDF. 


\section{REFERENCES}

Allaman, I., Bélanger, M., \& Magistretti, P. J. (2015). Methylglyoxal, the dark side of glycolysis. Frontiers in Neuroscience, 9, 23.

Alvarez, J., Alvarez-Illera, P., García-Casas, P., Fonteriz, R. I., \& Montero, M. (2020). The role of $\mathrm{Ca} 2+$ signaling in aging and neurodegeneration: insights from Caenorhabditis elegans models. Cells, $9(1)$.

An, C., Pu, X., Wang, Q., \& Zhang, H. (2019). Cistanche extracts ameliorates the neurotoxicity induced by hydrogen peroxide in new mutant DJ-1-transfected neuroblastoma cellular models. Brain and Behavior, 9(7), e01304.

Avila, G., de la Rosa, J. A., Monsalvo-Villegas, A., \& Montiel-Jaen, M. G. (2019). Ca2+ Channels mediate bidirectional signaling between sarcolemma and sarcoplasmic reticulum in muscle cells. Cells, $9(1)$.

Basso, V., Marchesan, E., \& Ziviani, E. (2020). A trio has turned into a quartet: DJ-1 interacts with the IP3R-Grp75-VDAC complex to control ER-mitochondria interaction. Cell Calcium, 87, 102186.

Blesa, J., Trigo-Damas, I., Quiroga-Varela, A., \& Jackson-Lewis, V. R. (2015). Oxidative stress and Parkinson's disease. Frontiers in Neuroanatomy, 9, 91.

Bonifati, V., Rizzu, P., van Baren, M. J., Schaap, O., Breedveld, G. J., Krieger, E., Dekker, M. C. J., Squitieri, F., Ibanez, P., Joosse, M., van Dongen, J. W., Vanacore, N., van Swieten, J. C., Brice, A., Meco, G., van Duijn, C. M., Oostra, B. A., \& Heutink, P. (2003). Mutations in the DJ-1 gene associated with autosomal recessive early-onset parkinsonism. Science, 299, 256-259.

Britzolaki, A., Saurine, J., Klocke, B., \& Pitychoutis, P. M. (2020). A role for SERCA pumps in the neurobiology of neuropsychiatric and neurodegenerative disorders. Advances in Experimental Medicine and Biology, 1131, 131-161.

Butterfield, D. A., \& Dalle-donne, I. (2014). Redox proteomics: from protein modifications to cellular dysfunction and disease. Mass Spectrometry Reviews, 33, 1-6.

Casani, S., Gómez-Pastor, R., Matallana, E., \& Paricio, N. (2013). Antioxidant compound supplementation prevents oxidative damage in a Drosophila model of Parkinson's disease. Free Radical Biology and Medicine, 61, 151-160.

Castro, J. P., Jung, T., Grune, T., \& Almeida, H. (2013). Actin carbonylation: from cell dysfunction to organism disorder. Journal of Proteomics, 92, 171-180.

Chernorudskiy, A. L., \& Zito, E. (2017). Regulation of calcium homeostasis by ER redox: A close-up of the ER/mitochondria connection. Journal of Molecular Biology, 429(5), $620-632$.

Chiaradia, E., Renzone, G., Scaloni, A., Caputo, M., Costanzi, E., Gambelunghe, A., Muzi, G., Avellini, L., Emiliani, C., \& Buratta, S. (2019). Protein carbonylation in dopaminergic cells exposed to rotenone. Toxicology Letters, 309, 20-32.

Dahl, R. (2017). A new target for Parkinsonâ $\epsilon^{T M}$ S disease: Small molecule SERCA activator CDN1163 ameliorates dyskinesia in 6-OHDA-lesioned rats. 
Di Domenico, F., Sultana, R., Ferree, A., Smith, K., Barone, E., Perluigi, M., Coccia, R., Pierce, W., Cai, J., Mancuso, C., Squillace, R., Wiengele, M., Dalle-Donne, I., Wolozin, B., \& Butterfield, D. A. (2012). Redox proteomics analyses of the influence of coexpression of wild-type or mutated LRRK2 and Tau on C. elegans protein expression and oxidative modification: relevance to Parkinson disease. Antioxidants \& Redox Signaling, 17(11), 1490-1506.

Erpapazoglou, Z., Mouton-Liger, F., \& Corti, O. (2017). From dysfunctional endoplasmic reticulum-mitochondria coupling to neurodegeneration. Neurochemistry International, 109, 171-183.

Feng, C.-W., Hung, H.-C., Huang, S.-Y., Chen, C.-H., Chen, Y.-R., Chen, C.-Y., Yang, S.-N., Wang, H.-M. D., Sung, P.-J., Sheu, J.-H., Tsui, K.-H., Chen, W.-F., \& Wen, Z.-H. (2016). Neuroprotective effect of the marine-derived compound 11-dehydrosinulariolide through DJ-1-related pathway in in vitro and in vivo models of Parkinson's disease. Marine Drugs, 14(10).

Feng, C., Chen, Y., Pan, J., Yang, A., Niu, L., Min, J., Meng, X., Liao, L., Zhang, K., \& Shen, L. (2017). Redox proteomic identification of carbonylated proteins in autism plasma: insight into oxidative stress and its related biomarkers in autism. Clinical Proteomics, $14,2$.

Gao, J.-W., Yamane, T., Maita, H., Ishikawa, S., Iguchi-Ariga, S. M. M., Pu, X.-P., \& Ariga, H. (2011). DJ-1-Mediated protective effect of protocatechuic aldehyde against oxidative stress in SH-SY5Y cells. Journal of Pharmacological Sciences, 115, 36-44.

Gehrig, S. M., van der Poel, C., Sayer, T. A., Schertzer, J. D., Henstridge, D. C., Church, J. E., Lamon, S., Russell, A. P., Davies, K. E., Febbraio, M. A., \& Lynch, G. S. (2012). Hsp72 preserves muscle function and slows progression of severe muscular dystrophy. Nature, 484(7394), 394-398.

Hecker, M., \& Wagner, A. H. (2018). Role of protein carbonylation in diabetes. Journal of Inherited Metabolic Disease, 41(1), 29-38.

Hemmati-Dinarvand, M., Saedi, S., Valilo, M., Kalantary-Charvadeh, A., Alizadeh Sani, M., Kargar, R., Safari, H., \& Samadi, N. (2019). Oxidative stress and Parkinson's disease: conflict of oxidant-antioxidant systems. Neuroscience Letters, 709, 134296.

Kaneko, M., Desai, B. S., \& Cook, B. (2014). Ionic leakage underlies a gain-of-function effect of dominant disease mutations affecting diverse P-type ATPases. Nature Genetics, $46(2), 144-151$.

Kang, S., Dahl, R., Hsieh, W., Shin, A., Zsebo, K. M., Buettner, C., Hajjar, R. J., \& Lebeche, D. (2016). Small molecular allosteric activator of the sarco/endoplasmic reticulum $\mathrm{Ca} 2+-$ ATPase (SERCA) attenuates diabetes and metabolic disorders. The Journal of Biological Chemistry, 291(10), 5185-5198.

Krajnak, K., \& Dahl, R. (2018). A new target for Alzheimer's disease: A small molecule SERCA activator is neuroprotective in vitro and improves memory and cognition in APP/PS1 mice. Bioorganic \& Medicinal Chemistry Letters, 28(9), 1591-1594.

Lam, A. K. M., \& Galione, A. (2013). The endoplasmic reticulum and junctional membrane communication during calcium signaling. Biochimica et Biophysica Acta, 1833(11), 
$2542-2559$.

Lavara-Culebras, E., Muñoz-Soriano, V., Gómez-Pastor, R., Matallana, E., \& Paricio, N. (2010). Effects of pharmacological agents on the lifespan phenotype of Drosophila DJ1beta mutants. Gene, 462, 26-33.

Lavara-Culebras, E., \& Paricio, N. (2007). Drosophila DJ-1 mutants are sensitive to oxidative stress and show reduced lifespan and motor deficits. Gene, 400, 158-165.

Lill, C. M. (2016). Genetics of Parkinson's disease. Molecular and Cellular Probes, 30(6), 386-396.

Lin, J. H., Walter, P., \& Yen, T. S. B. (2008). Endoplasmic reticulum stress in disease pathogenesis. Annual Review of Pathology, 3, 399-425.

Liu, Y., Ma, X., Fujioka, H., Liu, J., Chen, S., \& Zhu, X. (2019). DJ-1 regulates the integrity and function of ER-mitochondria association through interaction with IP3R3-Grp75VDAC1. Proceedings of the National Academy of Sciences of the United States of America, 116(50), 25322-25328.

Ma, Y.-G., Wang, J.-W., Bai, Y.-G., Liu, M., Xie, M.-J., \& Dai, Z.-J. (2017). Salidroside contributes to reducing blood pressure and alleviating cerebrovascular contractile activity in diabetic Goto-Kakizaki Rats by inhibition of L-type calcium channel in smooth muscle cells. BMC Pharmacology \& Toxicology, 18(1), 30.

Mazzio, E., \& Soliman, K. F. A. (2003). Pyruvic acid cytoprotection against 1-methyl-4phenylpyridinium, 6-hydroxydopamine and hydrogen peroxide toxicities in vitro. Neuroscience Letters, 337(2), 77-80.

Moraru, A., Cakan-Akdogan, G., Strassburger, K., Males, M., Mueller, S., Jabs, M., Muelleder, M., Frejno, M., Braeckman, B. P., Ralser, M., \& Teleman, A. A. (2017). THADA regulates the organismal balance between energy storage and heat production. Developmental Cell, 41(1), 72-81.

Park, J., Kim, S. Y., Cha, G.-H., Lee, S. B., Kim, S., \& Chung, J. (2005). Drosophila DJ-1 mutants show oxidative stress-sensitive locomotive dysfunction. Gene, 361, 133-139.

Park, S. W., Zhou, Y., Lee, J., Lee, J., \& Ozcan, U. (2010). Sarco(endo)plasmic reticulum $\mathrm{Ca} 2+-\mathrm{ATPase} 2 \mathrm{~b}$ is a major regulator of endoplasmic reticulum stress and glucose homeostasis in obesity. Proceedings of the National Academy of Sciences of the United States of America, 107(45), 19320-19325.

Poewe, W., Seppi, K., Tanner, C. M., Halliday, G. M., Brundin, P., Volkmann, J., Schrag, A.E., \& Lang, A. E. (2017). Parkinson disease. Nature Reviews. Disease Primers, 3, 17013.

Poon, H. F., Frasier, M., Shreve, N., Calabrese, V., Wolozin, B., \& Butterfield, D. A. (2005). Mitochondrial associated metabolic proteins are selectively oxidized in A30P alphasynuclein transgenic mice--a model of familial Parkinson's disease. Neurobiology of Disease, 18(3), 492-498.

Primeau, J. O., Armanious, G. P., Fisher, M. E., \& Young, H. S. (2018). The sarcoendoplasmic reticulum calcium ATPase. Sub-Cellular Biochemistry, 87, 229-258.

Qaisar, R., Bhaskaran, S., Ranjit, R., Sataranatarajan, K., Premkumar, P., Huseman, K., \& 
Van Remmen, H. (2019). Restoration of SERCA ATPase prevents oxidative stressrelated muscle atrophy and weakness. Redox Biology, 20, 68-74.

Rahate, K., Bhatt, L. K., \& Prabhavalkar, K. S. (2020). SERCA stimulation: A potential approach in therapeutics. Chemical Biology \& Drug Design, 95(1), 5-15.

Ren, R.-J., Dammer, E. B., Wang, G., Seyfried, N. T., \& Levey, A. I. (2014). Proteomics of protein post-translational modifications implicated in neurodegeneration. Translational Neurodegeneration, 3(1), 23.

Repici, M., \& Giorgini, F. (2019). DJ-1 in Parkinson's disease: Clinical insights and therapeutic perspectives. Journal of Clinical Medicine, 8(9).

Requejo-Aguilar, R., Lopez-Fabuel, I., Jimenez-Blasco, D., Fernandez, E., Almeida, A., \& Bolaños, J. P. (2015). DJ1 represses glycolysis and cell proliferation by transcriptionally up-regulating Pink1. The Biochemical Journal, 467, 303-310.

Sanders, L. H., \& Timothy Greenamyre, J. (2013). Oxidative damage to macromolecules in human Parkinson disease and the rotenone model. Free Radical Biology \& Medicine, 62, 111-120.

Sanyal, S., Consoulas, C., Kuromi, H., Basole, A., Mukai, L., Kidokoro, Y., Krishnan, K. S., \& Ramaswami, M. (2005). Analysis of conditional paralytic mutants in Drosophila sarco-endoplasmic reticulum calcium ATPase reveals novel mechanisms for regulating membrane excitability. Genetics, 169(2), 737-750.

Sanz, F. J., Solana-Manrique, C., Muñoz-soriano, V., Calap-quintana, P., Moltó, M. D., \& Paricio, N. (2017). Identification of potential therapeutic compounds for Parkinson's disease using Drosophila and human cell models. Free Radical Biology and Medicine, $108,683-691$.

Shen, L., Chen, C., Yang, A., Chen, Y., Liu, Q., \& Ni, J. (2015). Redox proteomics identification of specifically carbonylated proteins in the hippocampi of triple transgenic Alzheimer's disease mice at its earliest pathological stage. Journal of Proteomics, 123, $101-113$.

Shevchenko, A., Wilm, M., Vorm, O., \& Mann, M. (1996). Mass spectrometric sequencing of proteins silver-stained polyacrylamide gels. Analytical Chemistry, 68(5), 850-858.

Shtifman, A., Zhong, N., Lopez, J. R., Shen, J., \& Xu, J. (2011). Altered Ca2+ homeostasis in the skeletal muscle of DJ-1 null mice. Neurobiology of Aging, 32(1), 125-132.

Solana-Manrique, C., Moltó, M. D., Calap-Quintana, P., Sanz, F. J., Llorens, J. V., \& Paricio, N. (2019). Drosophila as a model system for the identification of pharmacological therapies in neurodegenerative diseases. In M. Mutsuddi \& A. Mukrherjee (Eds.), Insights into human neurodegeneration: Lessons learnt from Drosophila (1st ed., pp. 433-467). Springer Nature.

Solana-Manrique, C., Sanz, F. J., Ripollés, E., Bañó, M. C., Torres, J., Muñoz-Soriano, V., \& Paricio, N. (2020). Enhanced activity of glycolytic enzymes in Drosophila and human cell models of Parkinson's disease based on DJ-1 deficiency. Free Radical Biology \& Medicine, 158, 137-148.

Sultana, R., Perluigi, M., \& Butterfield, D. A. (2013). Lipid peroxidation triggers 
neurodegeneration: a redox proteomics view into the Alzheimer disease brain. Free Radical Biology \& Medicine, 62, 157-169.

Sunderhaus, E. R., Law, A. D., \& Kretzschmar, D. (2019). ER responses play a key role in Swiss-Cheese/Neuropathy Target Esterase-associated neurodegeneration. Neurobiology of Disease, 130, 104520.

Suzuki, Y. J., Carini, M., \& Butterfield, D. A. (2010). Protein carbonylation. Antioxidants \& Redox Signaling, 12(3), 323-325.

Tamarit, J., de Hoogh, A., Obis, E., Alsina, D., Cabiscol, E., \& Ros, J. (2012). Analysis of oxidative stress-induced protein carbonylation using fluorescent hydrazides. Journal of Proteomics, 75(12), 3778-3788.

Uhlén, M., Fagerberg, L., Hallström, B. M., Lindskog, C., Oksvold, P., Mardinoglu, A., Sivertsson, Å., Kampf, C., Sjöstedt, E., Asplund, A., Olsson, I., Edlund, K., Lundberg, E., Navani, S., Szigyarto, C. A.-K., Odeberg, J., Djureinovic, D., Takanen, J. O., Hober, S., ... Pontén, F. (2015). Proteomics. Tissue-based map of the human proteome. Science, $347(6220), 1260419$.

Uhlén, M., Oksvold, P., Fagerberg, L., Lundberg, E., Jonasson, K., Forsberg, M., Zwahlen, M., Kampf, C., Wester, K., Hober, S., Wernerus, H., Björling, L., \& Ponten, F. (2010). Towards a knowledge-based Human Protein Atlas. Nature Biotechnology, 28(12), 12481250.

Wang, Z., Liu, J., Chen, S., Wang, Y., Cao, L., Zhang, Y., Kang, W., Li, H., Gui, Y., Chen, S., \& Ding, J. (2011). DJ-1 modulates the expression of Cu/Zn-superoxide dismutase-1 through the Erk1/2-Elk1 pathway in neuroprotection. Annals of Neurology, 70, 591-600.

Zaichick, S. V, McGrath, K. M., \& Caraveo, G. (2017). The role of Ca2+ signaling in Parkinson's disease. Disease Models \& Mechanisms, 10(5), 519-535. https://doi.org/10.1242/dmm.028738

Žižková, P., Viskupičová, J., Blaškovič, D., Štrosová, M. K., Žarkovič, N., \& Horáková, L. (2014). Sarcoplasmic reticulum Ca2+-ATPase from rabbit skeletal muscle modified by peroxynitrite. Journal of Enzyme Inhibition and Medicinal Chemistry, 29(4), 563-570.

Žižková, P., Viskupičová, J., Heger, V., Racková, L., Majeková, M., \& Horáková, L. (2018). Dysfunction of SERCA pumps as novel mechanism of methylglyoxal cytotoxicity. Cell Calcium, 74, 112-122. 


\section{FIGURE LEGENDS}

Figure 1. Representative 2D gels obtained in the redox proteomics assays from 15-day-old control $(y, w)$ and $D J-1 \beta$ mutant flies. (A) Representative 2D gels stained with Sypro Ruby to visualize total protein content and with (B) Bodipy to reveal carbonyl groups in whole protein extracts of 15-day-old control $(y, w)$ and $D J-1 \beta$ mutant flies. The spots showing increased carbonylation levels in PD model flies compared to controls and selected for protein identification are indicated with arrows. The spot numbers are the same as those listed in Table 1.

Figure 2. Analysis of SERCA activity in $D J-1 \beta$ mutant flies. (A) SERCA activity was measured in 15-day-old $y, w$ control flies, and in $i R d S E R C A$ and $D J-1 \beta$ mutant flies. In all cases results were relativized to data obtained from 15-day-old $y, w$ control flies and are expressed as arbitrary units (a.u.). (B) Analysis of $d S E R C A$ gene expression levels by RTqPCR analysis. $d S E R C A$ expression levels were measured in 15-day-old $D J-1 \beta$ mutants and $i R d S E R C A$ flies. Results are relativized to data obtained in control flies for each genotype ( $y, w$ and arm-GAL4/+ flies, respectively), and are expressed as arbitrary units (a.u.). For (A) error bars show s.d. from three independent experiments in which three biological replicates were used. For (B) error bars show s.d. from four independent experiments ${ }^{*}, P<0.05$; ***, $P<0.001)$.

Figure 3. Analysis of SERCA activity and carbonylation levels in DJ-1-deficient human cells. (A) SERCA activity was measured in $D J$-1-deficient cells under OS conditions induced with $50 \mu \mathrm{M} \mathrm{H}_{2} \mathrm{O}_{2}$. (B) Graphical representation of ATP2A1 (SERCA1) and ATP2A2 (SERCA2) expression levels in $D J$-1-deficient cells under OS condition induced with $50 \mu \mathrm{M}$ $\mathrm{H}_{2} \mathrm{O}_{2}$. Results are referred to data obtained in $p L K O .1$ control cells under the same OS condition, and are expressed as arbitrary units (a.u.). In both cases, tubulin expression levels were measured and used as an internal control for RNA amount in each sample. (C) SERCA carbonylation levels were detected by inmunoprecipitation and post-Western blot analysis in $D J$-1-deficient cells under OS conditions induced with $50 \mu \mathrm{M} \mathrm{H}_{2} \mathrm{O}_{2}$. Left panel shows representative western blots and the right panel constitutes its graphical representation. Results were relativized to data obtained in $p L K O .1$ control cells also treated with $50 \mu \mathrm{M}$ $\mathrm{H}_{2} \mathrm{O}_{2}$, and are expressed as arbitrary units (a.u). Error bars show s.d. from three replicates and 
three independent experiments in $\mathrm{A}$ and $\mathrm{C}$, and from four independent experiments in $\mathrm{B}\left({ }^{*}, P\right.$ $<0.05 ; * * *, P<0.001)$.

Figure 4. Effect of CDN1163 treatments on phenotypes exhibited by $D J-1 \beta$ mutant flies. (A) Motor performance of $D J-1 \beta$ mutant flies treated with $50 \mu \mathrm{M}$ CDN1163 was analyzed using climbing assays. (B) Levels of $\mathrm{H}_{2} \mathrm{O}_{2}$ production in $D J-1 \beta$ mutant flies treated with $50 \mu \mathrm{M}$ CDN1163 were analyzed by using the Amplex $\mathrm{H}_{2} \mathrm{O}_{2}$ Red Kit (Invitrogen). Data were expressed as arbitrary units (a.u.) per mg of proteins. (C) Protein carbonylation levels in $D J$ $1 \beta$ mutant flies treated with $50 \mu \mathrm{M}$ CDN1163 were analyzed by absorbance. (D) SERCA activity was measured in 15-day-old $D J-1 \beta$ mutant flies cultured with $50 \mu \mathrm{M}$ CDN1163. In all cases, results were referred to data obtained in flies cultured in vehicle medium (DMSO). Error bars show s.d. from three replicates and three independent experiments $(*, P<0.05$; **, $P<0.01 ; * * *, P<0.001)$.

Figure 5. Effect of CDN1163 treatments in viability and SERCA activity in DJ-1-deficient cells. (A) Dosage-dependent effect of SERCA in OS-induced cell death. Viability of DJ-1deficient cells was measured by MTT assays in presence of OS (induced with $100 \mu \mathrm{M} \mathrm{H}_{2} \mathrm{O}_{2}$ ). Cells were either cultured in vehicle medium (DMSO) or treated with five different concentrations of CDN1163. Results were relativized to data obtained from $D J$-1-deficient cells cultured in vehicle (-) in presence of OS conditions. (B) SERCA activity in DJ-1deficient cells treated with $5 \mu \mathrm{M}$ CDN1163 in presence of OS conditions. Results were relativized to data from untreated $D J$ - 1 -deficient cells cultured in vehicle (DMSO). In all cases, error bars show s.d. from three replicates and three independent experiments $\left(^{*}, P<\right.$ $0.05 ; * *, P<0.01 ; * * *, P<0.001)$.

\section{SUPPLEMENTARY FIGURE}

Figure S1. Analysis of locomotor performance and lifespan in iRdSERCA mutant flies. (A) Motor performance of $i R d S E R C A$ mutant flies was analyzed using climbing assays. Error bars show s.d. from three independent experiments (***, $P<0.001)$. (B) Comparison of lifespan curves of $i R d S E R C A$ mutant (white squares) and arm-GAL4/+ control flies (black diamond). The median and maximum lifespan values are as follows: 68 and 89 days for arm-GAL4/+ controls; 10 and 21 days for $i R d S E R C A$ mutant flies. The significance of the difference 
bioRxiv preprint doi: https://doi.org/10.1101/2020.11.19.389841; this version posted November 19, 2020. The copyright holder for this preprint (which was not certified by peer review) is the author/funder. All rights reserved. No reuse allowed without permission.

between survival curves was analyzed using Kaplan-Meier log-rank statistical test $(* * * *, P<$ $0.0001)$. 
Table 1. Proteins identified by mass spectrometry that showed increased carbonylation levels in 15-day-old $D J$ - $1 \beta$ mutant flies.

\begin{tabular}{|c|c|c|c|c|c|c|}
\hline Spot & Protein identified & Drosophila gene & $\begin{array}{c}\text { Identification } \\
\text { method }^{\mathrm{a}}\end{array}$ & $\operatorname{Cov}(\%)^{b}$ & $\begin{array}{c}\text { Protein } \\
\text { score }\end{array}$ & $\begin{array}{c}\text { Oxidation } \\
\text { Fold }^{\mathrm{c}} \\
\end{array}$ \\
\hline 175 & V-type proton ATPase catalytic subunit A isoform 2 & Vha68-1 & LC-MS/MS & 52 & 53 & 1.8 \\
\hline 336 & Tyrosyl-tRNA synthethase & Aats-tyr & LC-MS/MS & 32.2 & 23 & 1.6 \\
\hline 384 & Myosin heavy chain, muscle & Mhc & LC-MS/MS & 12.8 & 52 & 1.7 \\
\hline 496 & Enolase & Eno & MS-MS/MS & 46 & 254 & 1.4 \\
\hline \multirow{2}{*}{555} & Probable cytrate synthase, mitocondrial & $K d n$ & LC-MS/MS & 13.4 & 12 & \multirow{2}{*}{2.1} \\
\hline & ATP-dependent 6-phosphofructokinase & $P f k$ & LC-MS/MS & 10.3 & 16 & \\
\hline 625 & Vitellogenin-3 & $Y p 3$ & MS-MS/MS & 50 & 310 & 1.4 \\
\hline 716 & Actin & $\begin{array}{l}\operatorname{actin} 5 c, \operatorname{actin} 42 A, \\
\operatorname{actin}\end{array}$ & MS-MS/MS & 22 & 160 & 1.6 \\
\hline 731 & ATP-dependent 6-phosphofructokinase & $P f k$ & LC-MS/MS & 20.3 & 28 & 1.6 \\
\hline 795 & Vitellogenin-2 & $Y p 2$ & MS-MS/MS & 11 & 180 & 2.4 \\
\hline 971 & Voltage-dependent anion-selective cannel & porin & MS-MS/MS & 58 & 330 & 1.4 \\
\hline 1061 & Arginine kinase & $\operatorname{argk}$ & MS-MS/MS & 43 & 407 & 2.8 \\
\hline 1310 & Calcium-transporting ATPase sarcoplasmic & Ca-P60A & LC-MS/MS & 5.5 & 8 & 2 \\
\hline
\end{tabular}

${ }^{\mathrm{a}}$ Proteins were identified either by tandem mass spectrometry (MS-MS/MS) or liquid chromatography and tandem mass spectrometry (LC-MS/MS)

${ }^{\mathrm{b}}$ Protein sequence coverage

${ }^{\mathrm{c}}$ Oxidation fold values present $\mathrm{P}<0.05$ versus the control 
A
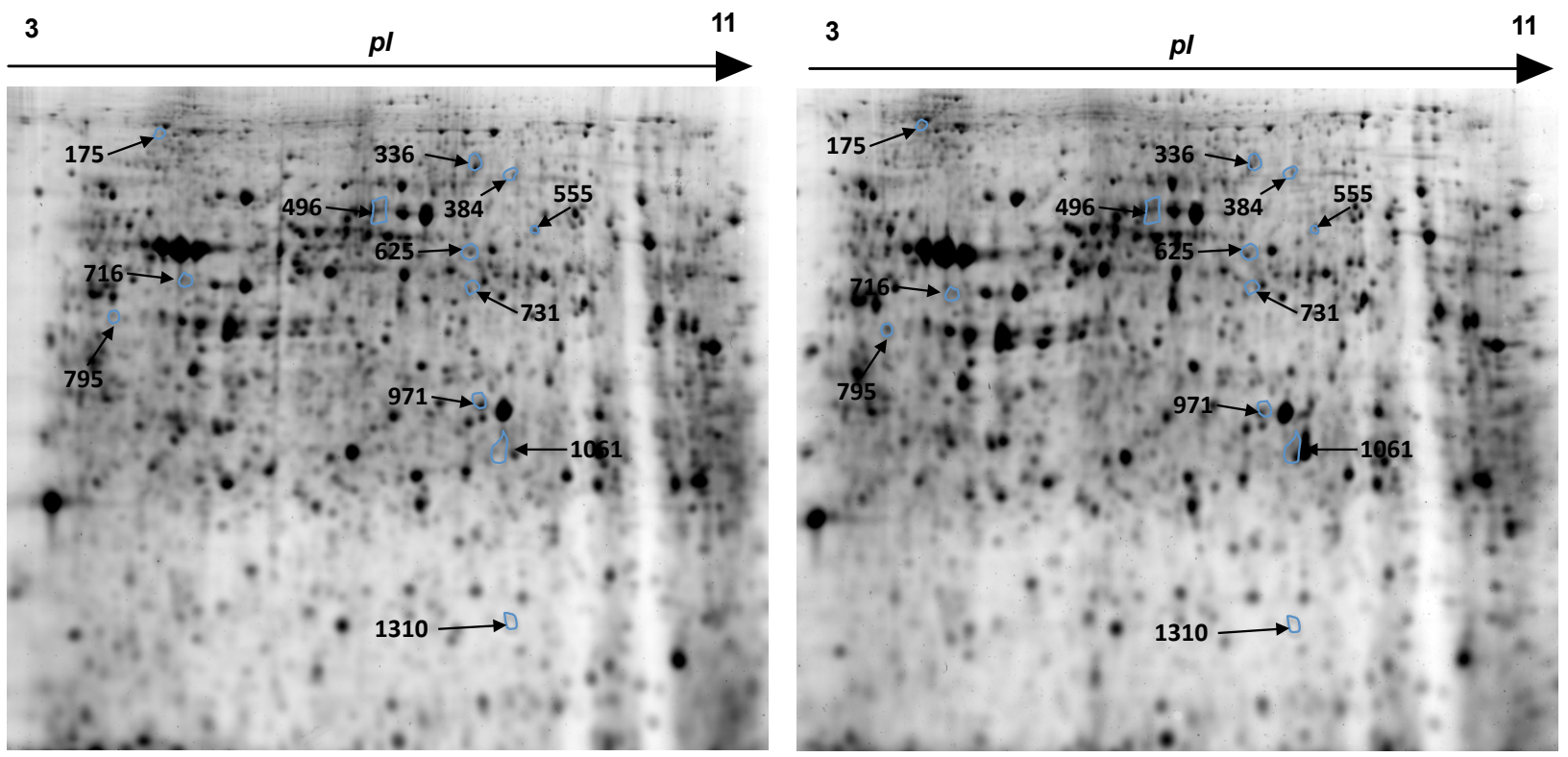

B

Bodipy - y,w

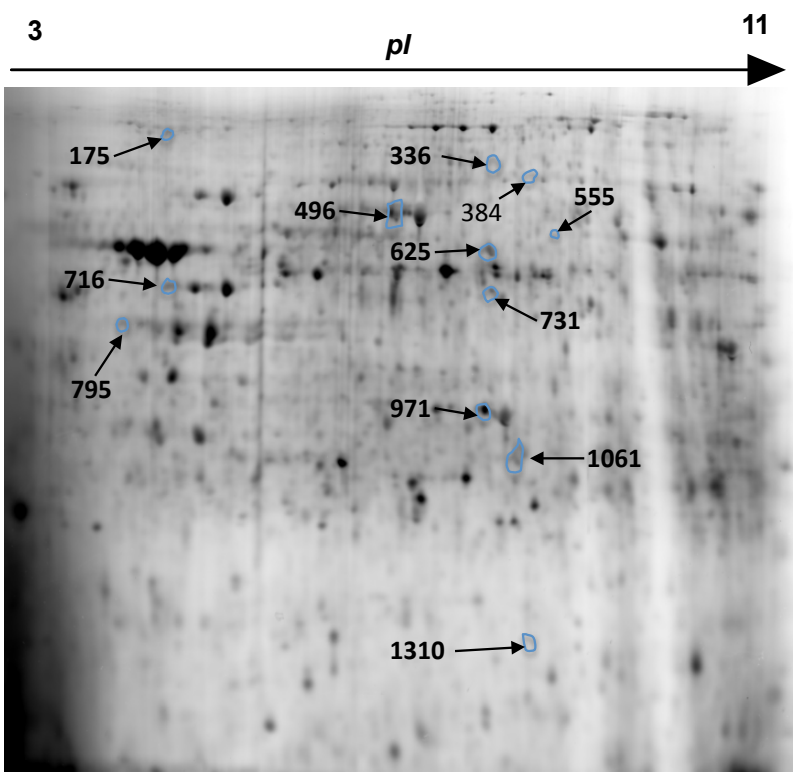

Bodipy - DJ-1 $\beta$

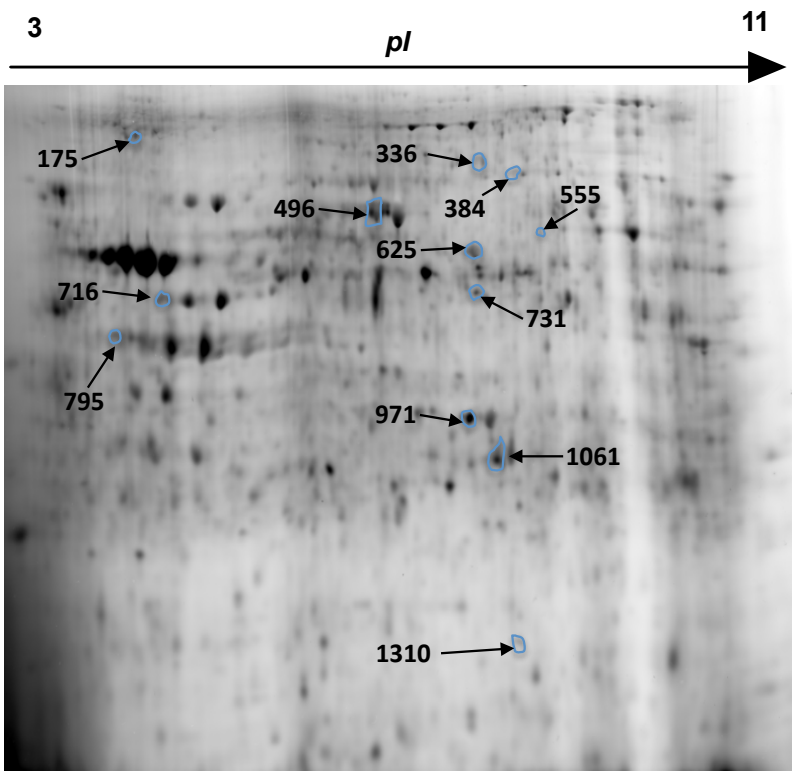


FIGURE 2

A
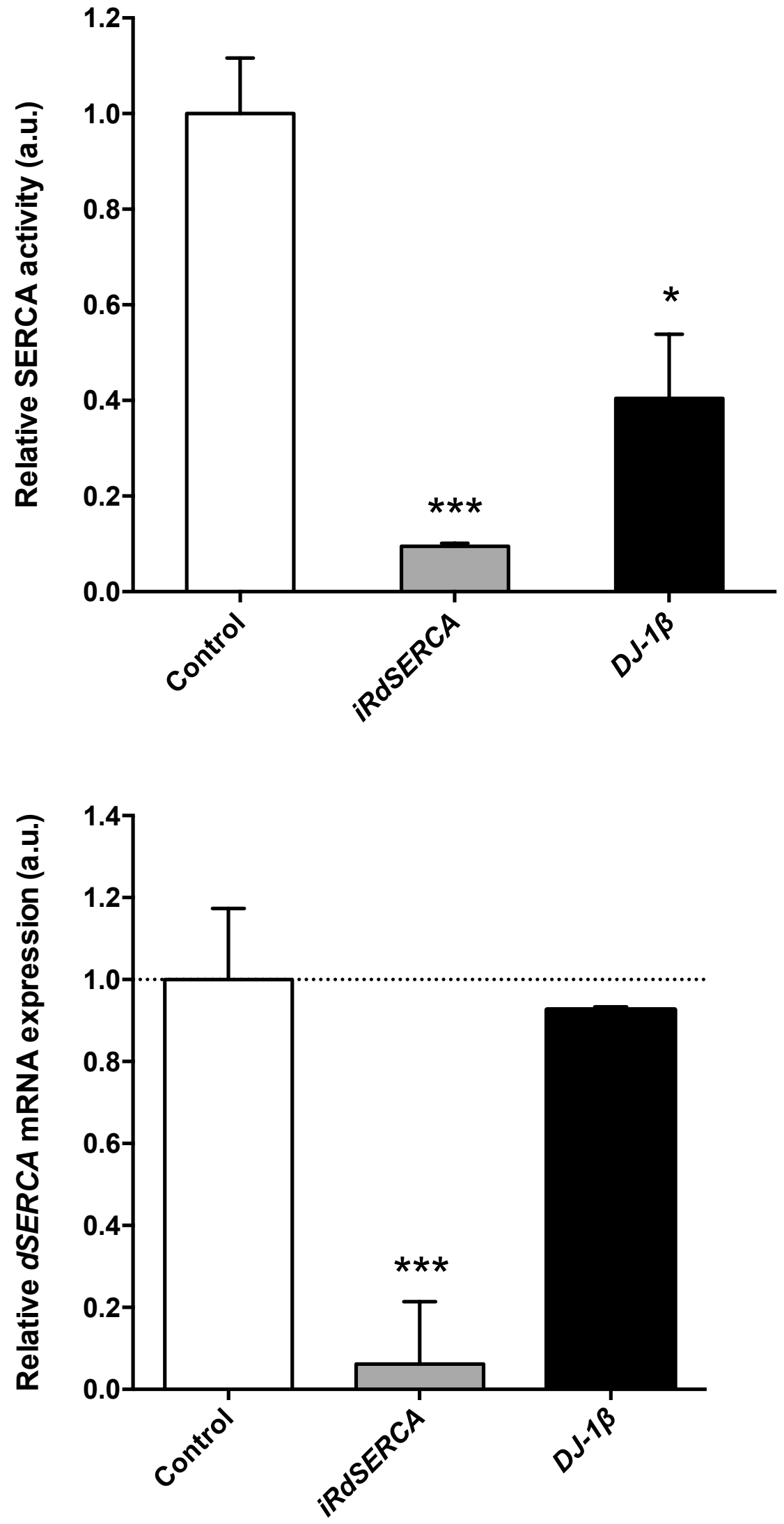
A

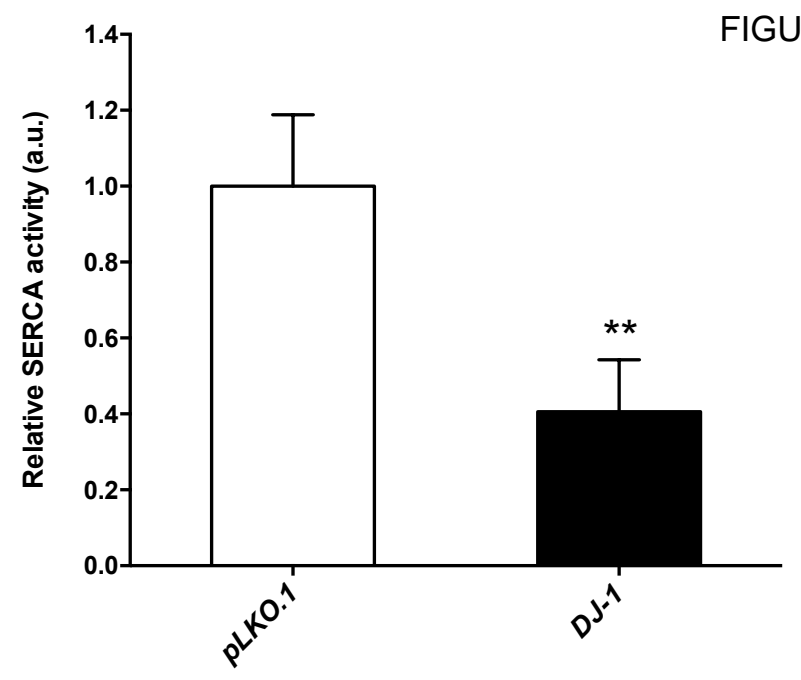

B

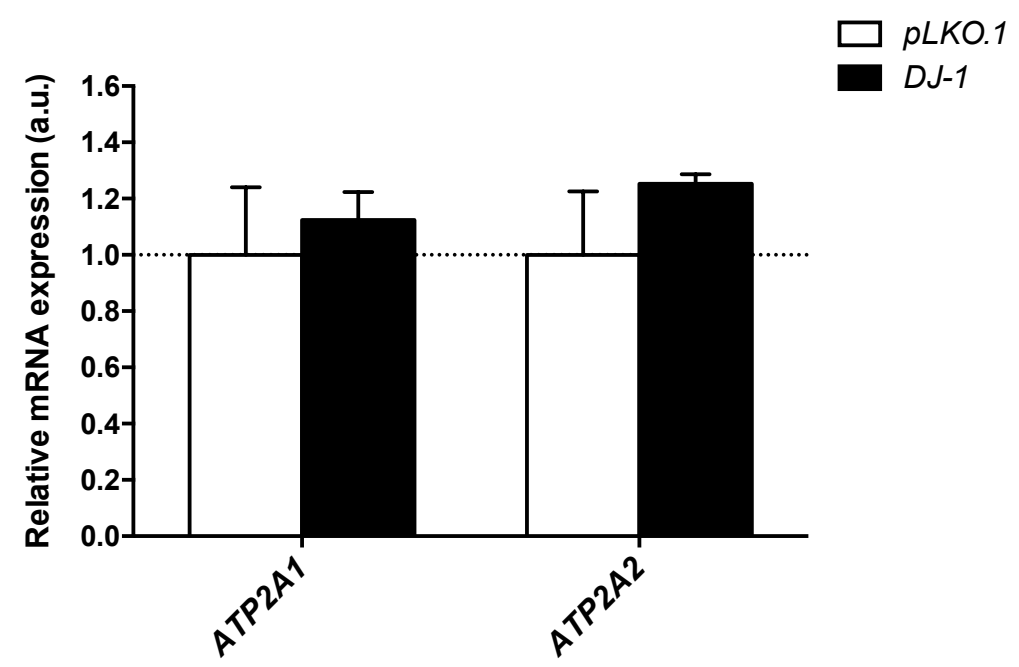

C

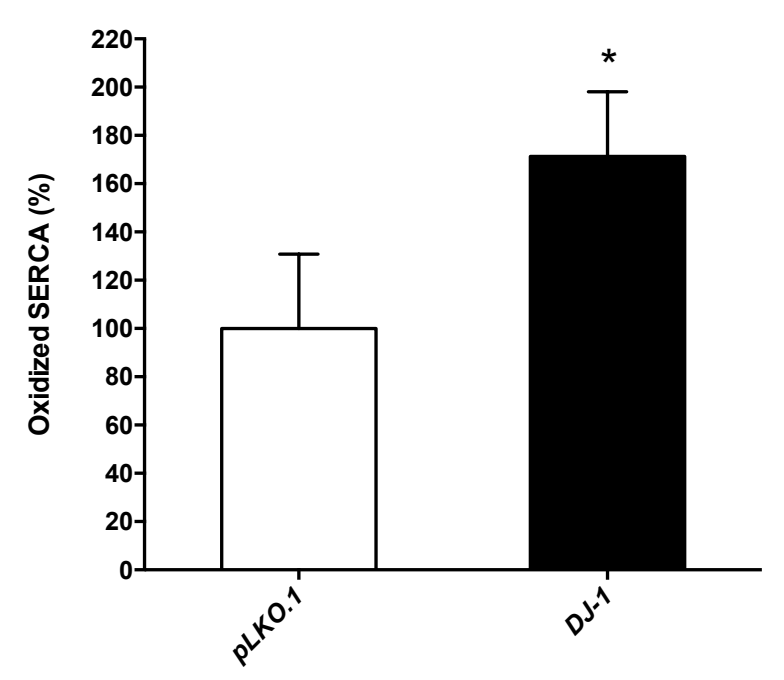

SERCA IP + DNP-derivate + WB

pLKO.1 DJ-1

SERCA IP + WB
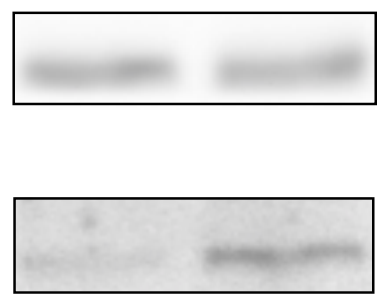

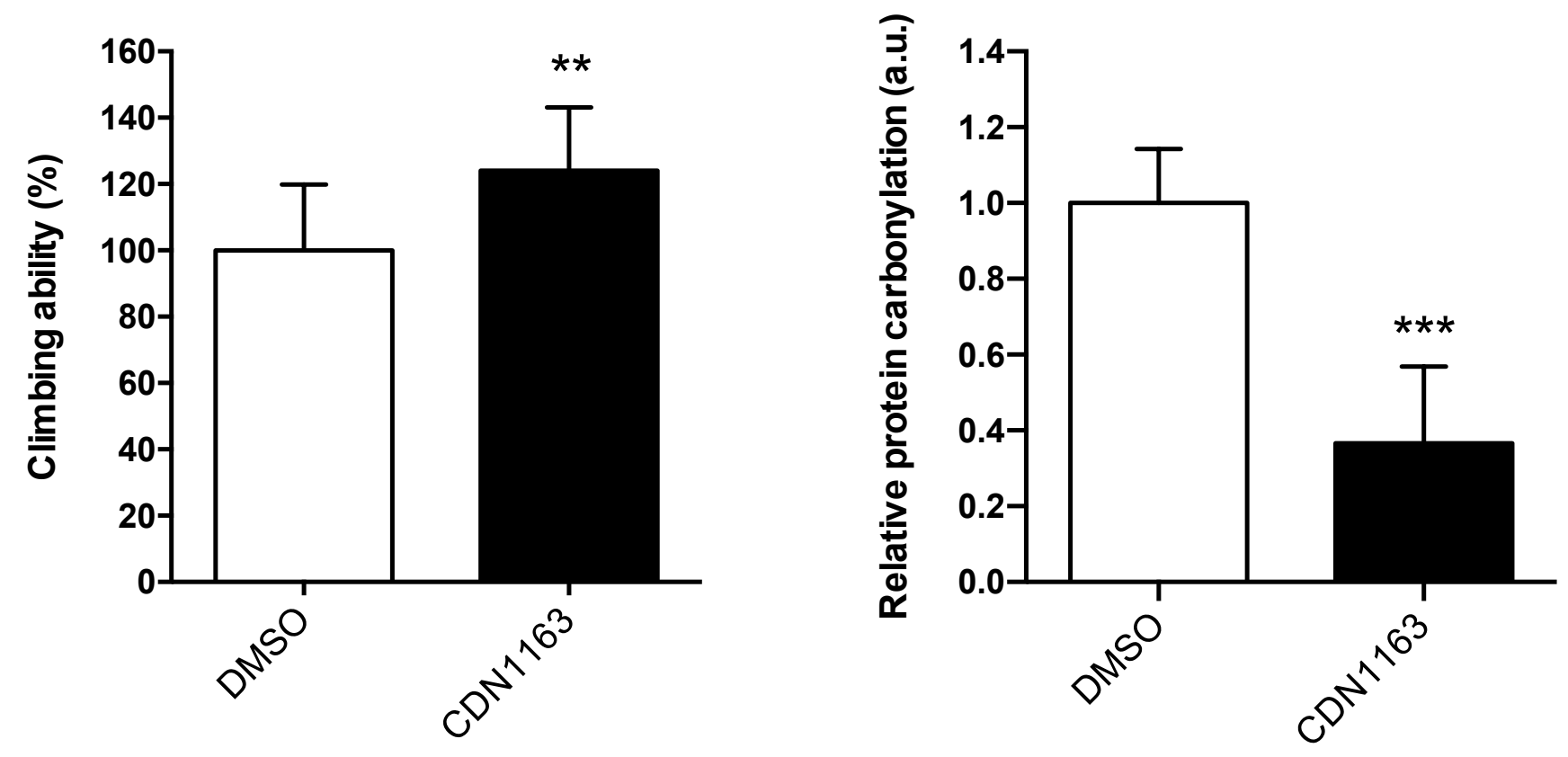

C

D
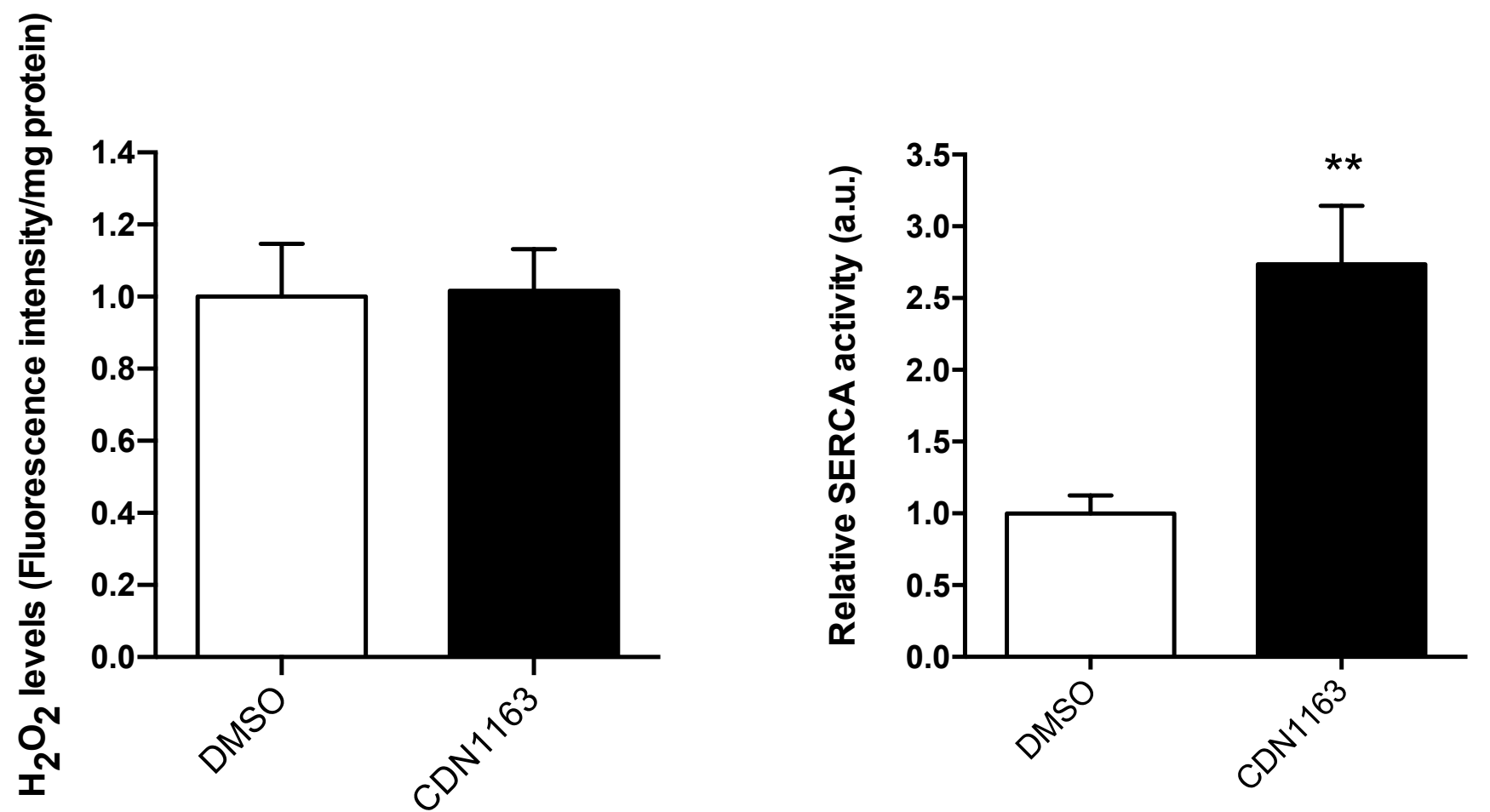


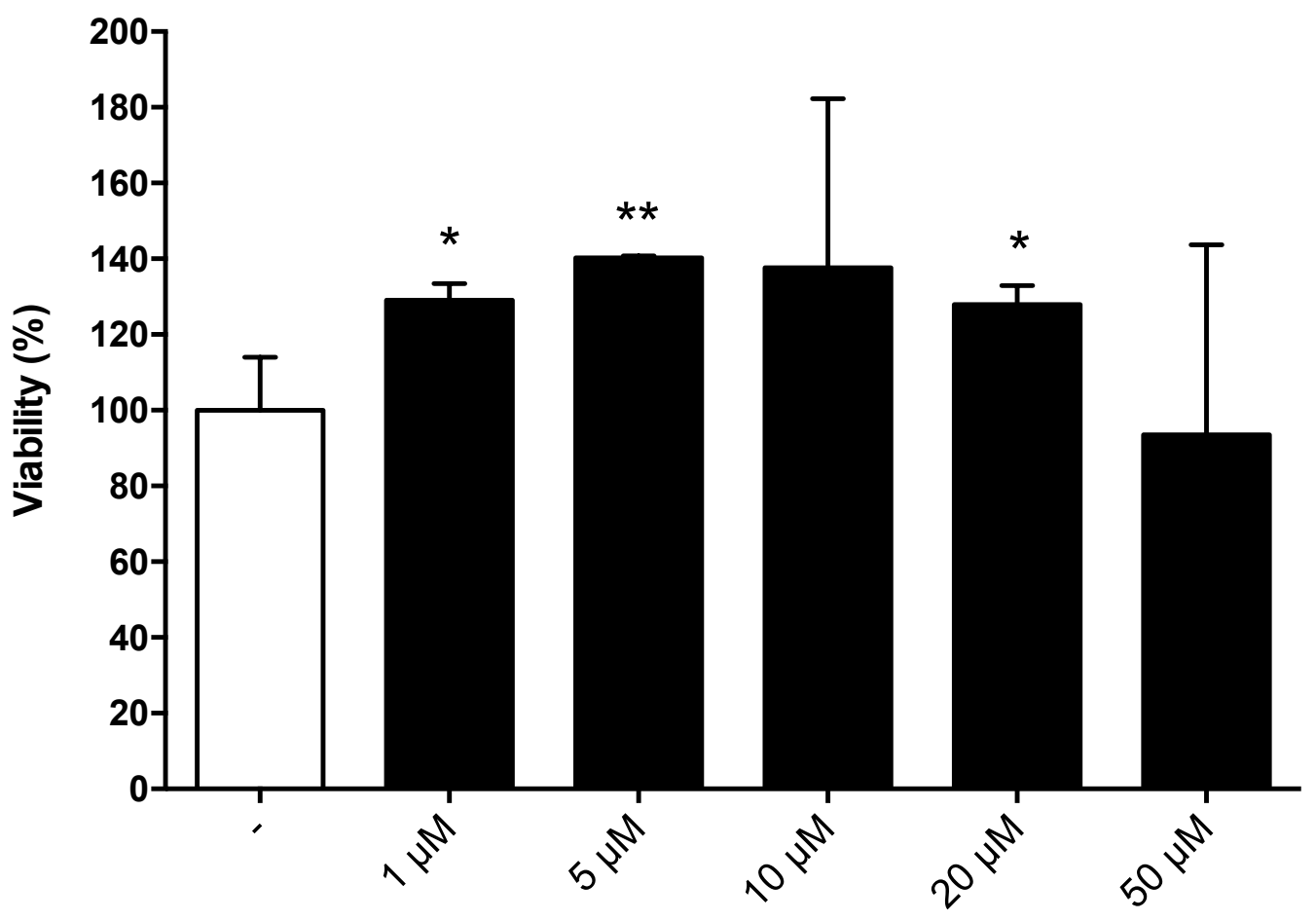

[CDN1163]

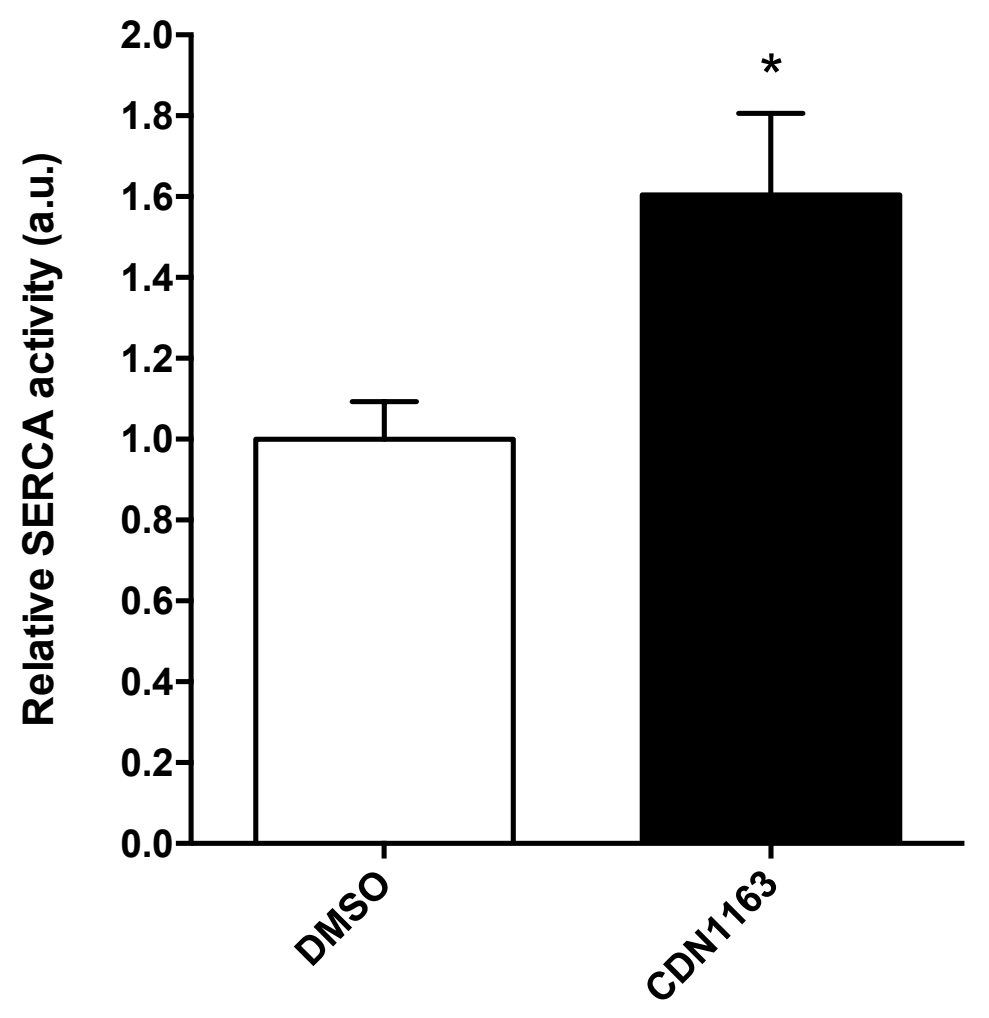


Table S1. Functional role of the highly carbonylated proteins identified in the redox proteomics assay.

\begin{tabular}{|c|c|c|}
\hline $\begin{array}{c}\text { Spot } \\
\text { number }\end{array}$ & Protein & Funcional role \\
\hline 175 & $\begin{array}{l}\text { V-type proton ATPase catalytic subunit A } \\
\text { isoform } 2\end{array}$ & $\begin{array}{l}\text { Catalytic subunit of the peripherial VI complex of vacuolar ATPase (V-ATPase). V-ATPase is } \\
\text { responsible of acidifying a variety of intracelllular compartemts in eukaryotic cells }\end{array}$ \\
\hline 336 & Tyrosyl-tRNA synthethase & $\begin{array}{l}\text { Exhibits tyrosine-tRNA ligase activity, catalyzes the ligation of tyrosine to its cognate tRNAs in the } \\
\text { cytoplasm }\end{array}$ \\
\hline 384 & Myosin heavy chain, muscle & Muscle contraction \\
\hline 496 & Enolase & Exhibits phosphopyruvate hydratase activity. Enolase is involved in glucose homeostasis \\
\hline \multirow[b]{2}{*}{555} & Probable cytrate synthase, mitocondrial & Plays a role in controlling neuronal activity and seizure susceptibility \\
\hline & ATP-dependent 6-phosphofructokinase & $\begin{array}{l}\text { Catalyzes the phosphorylation of D-fructose 6-phosphate to fructose 1,6-bisphosphate by ATP, the } \\
\text { first committing step of glycolysis }\end{array}$ \\
\hline 625 & Vitellogenin-3 & Vitellogenin is the major yolk protein of eggs where it is used as a food source during embryogenesis \\
\hline 716 & Actin & $\begin{array}{l}\text { Actin are highly conserved proteins that are involved in various types of cells motility and are } \\
\text { ubiquitously expressed in all eukaryotic cells. Multiple isoforms are involved in various cellular } \\
\text { functions such as cytoeskeleton structure, cell motility, chromosome movement and muscle } \\
\text { contraction }\end{array}$ \\
\hline 731 & ATP-dependent 6-phosphofructokinase & $\begin{array}{l}\text { Catalyzes the phosphorylation of D-fructose 6-phosphate to fructose 1,6-bisphosphate by ATP, the } \\
\text { first committing step of glycolysis }\end{array}$ \\
\hline 795 & Vitellogenin-2 & Vitellogenin is the major yolk protein of eggs where it is used as a food source during embryogenesis \\
\hline 971 & Voltage-dependent anion-selective cannel & Forms a channel through the cell membrane that allows diffusion of small hydrophilic molecules \\
\hline 1061 & Arginine kinase & $\begin{array}{l}\text { Exhibits creatine kinase activity and transfers a phosphate group, usually from ATP, to creatine } \\
\text { substrate }\end{array}$ \\
\hline 1310 & Calcium-transporting ATPase sarcoplasmic & $\begin{array}{l}\text { This magnesium-dependent enzyme catalyzes the hydrolysis of ATP coupled with the transport of } \\
\text { calcium to the endoplasmic reticulum }\end{array}$ \\
\hline
\end{tabular}
calcium to the endoplasmic reticulum 

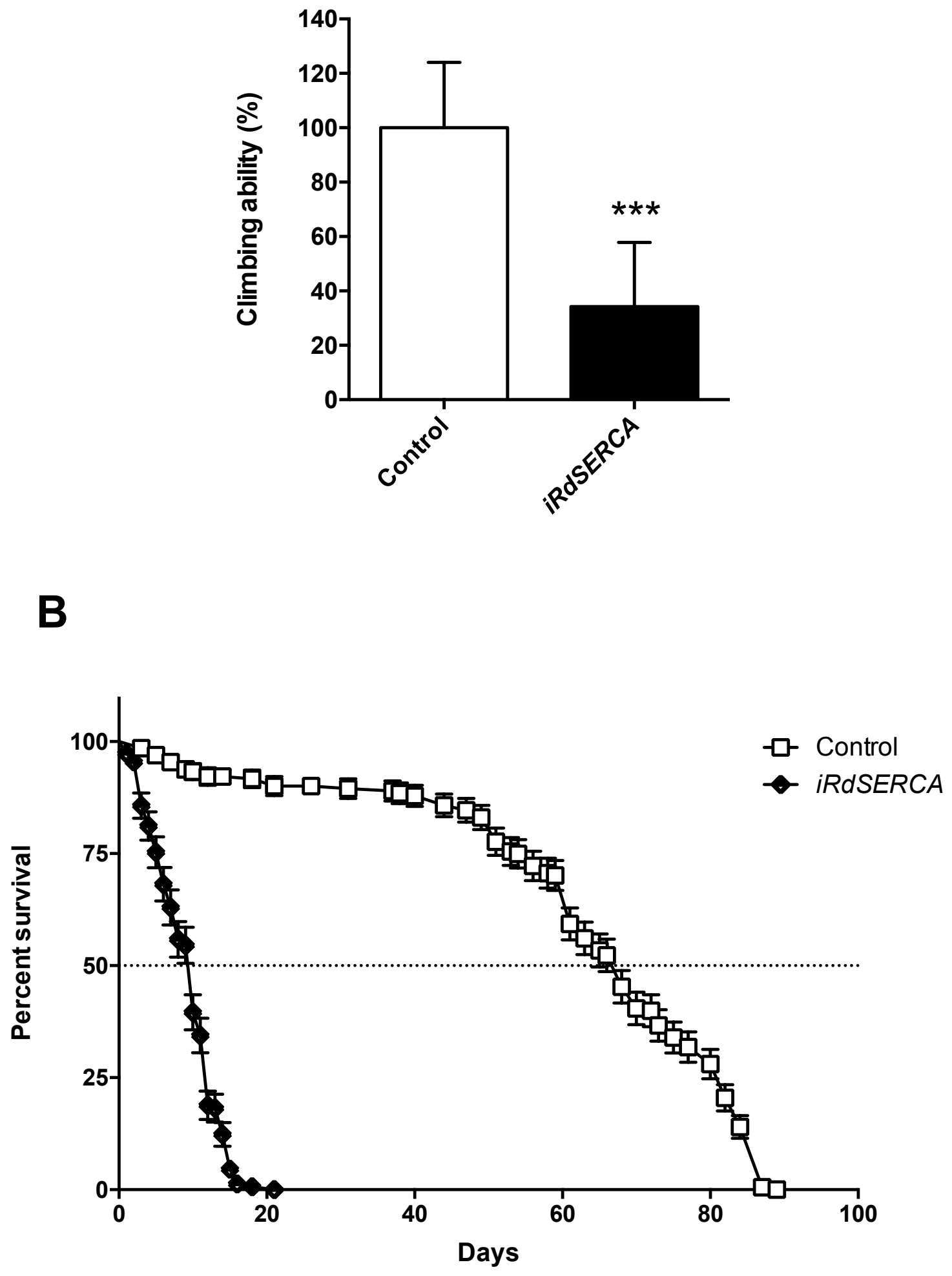